\title{
RESUMOS DAS PALESTRAS PROFERIDAS NO I SIMPÓSIO DE ATUALIZAÇÃO EM HIPERTENSÃO ARTERIAL DA UNIDADE DE HIPERTENSÃO DA DIVISÃO DE CARDIOLOGIA DO HCFMRP-USP, REALIZADO EM 18-19 DE AGOSTO DE 1995 NO CAMPUS DA USP- RIBEIRÃO PRETO
}

\section{Apresentação}

A moderna concepção da hipertensão arterial corrobora definição sindrômica, enunciada no início deste século. Entretanto, vários outros aspectos só recentemente se tornaram reconhecidos. Assim, Weber redefine a hipertensão arterial como síndrome caracterizada por: aumento da pressão arterial, dislipidemia (com sinergismo para doença arterial coronariana), resistência à insulina, tendência à obesidade centrípeta, microalbuminúria, aumento da atividade dos fatores de coagulação, redução da complacência arterial, hipertrofia e disfunção diastólica do ventrículo esquerdo.

A hipertensão arterial, que penaliza enorme contigente de indivíduos em todos os países do mundo, somente na última década vem recebendo a devida, ainda que restrita, atenção por parte das sociedades médicas afeitas a seu estudo. Pouco, ou quase nada se tem de conhecimento epidemiológico a nível nacional. A implementação dos Departamentos de Hipertensão das Sociedades Brasileira de Cardiologia e Nefrologia e, mais recentemente, a fundação da Sociedade Brasileira de Hipertensão, foram passos decisivos na criação de organismos voltados ao estudo e difusão dos conhecimentos sobre hipertensão no Brasil. De parte das instituições oficiais, seja por descaso, seja por insuficiência de recursos alocados para este fim, não se esclarece a população sobre suas conseqüências, assim como não se diagnosticam novos hipertensos e pouco se faz para tratar aqueles, já diagnosticados.

FERNANDO NOBRE

Coordenador da Unidade de Hipertensão da

Divisão de Cardiologia - HCFMRP-USP

A criação da Unidade de Hipertensão da Divisão de Cardiologia do Hospital das Clínicas de Ribeirão Preto objetivou direcionar as atividades deste setor do Departamento de Clínica Médica, desta Instituição, para o trabalho em hipertensão arterial, no contexto do trinômio-base das funções desta Escola de Medicina: assistência, pesquisa e ensino.

As já implementadas atividades, apontando para estes objetivos, caminham céleres.

Esta será, sem dúvida, mais uma contribuição no sentido de se priorizar, nesta unidade, o trabalho com esta síndrome que afeta, aproximadamente, 15 milhões de indivíduos em nosso País. Representa um movimento de, aproximadamente, 100 milhões de dólares americanos ao ano do mercado farmacêutico nacional e, de forma direta ou não, constitui a maior causa de afastamento do trabalho.

Este simpósio, que se realizará bianualmente, está absolutamente em consonância com estes principios, que definem as bases de nosso trabalho.

A especial qualificação e excelência dos palestrantes, e a temática do mais alto nível, servirão para colocá-lo entre os principais eventos do gênero em nosso País.

A elaboração desta sinopse sedimenta e perpetua, através do prestigioso periódico que a publica, os conceitos que serão discutidos ao longo destes dois dias de atividades.

JOSÉ ANTONIO MARIN NETO

Coordenador da Divisão de Cardiologia do Departamento de Clínica Médica - HCFMRP-USP 


\section{ASPECTOS METABÓLICOS DA HIPERTENSÃO ARTERIAL - METABOLISMO DE HIDRATOS DE CARBONO E INSULINA}

\author{
Maria Teresa Zanella \\ Professor Adjunto da Disciplina de Endocrinologia da \\ Escola Paulista de Medicina - SP
}

Hipertensão arterial é achado muito freqüente no diabete melito, quer no tipo dependente de insulina, quer naquele não dependente de insulina. Assim, no diabete não dependente de insulina (do tipo II) a hipertensão é duas vezes mais freqüente do que na população não diabética. Nos pacientes com diabete dependente de insulina, também chamado diabete tipo I, a hipertensão é restrita aos pacientes que desenvolvem nefropatia, o que ocorre em $30-40 \%$ dos pacientes com diabete tipo I. No passado, a hipertensão arterial do diabete do tipo I era admitida como consequência da insuficiência renal que sobrevem à nefropatia diabética. Atualmente, entretanto, nosso conhecimento aumentou, significantemente, sobre a complexa interrelação entre homeostase da glicose, regulação da pressão arterial e função renal no diabete. Embora ambos os tipos de diabete compartilhem de um excesso de sódio permutável e, também, de uma maior reatividade vascular a agentes pressores, a hipertensão arterial se desenvolve por mecanismos diferentes no diabete tipo I e no diabete tipo II.

No diabete tipo I, a hipertensão se associa ao aparecimento da microalbuminúria (excreção urinária de albumina $>20 \mu \mathrm{g} / \mathrm{min}$ ). Nesta etapa da nefropatia diabética, denominada nefropatia incipiente, a função glomerular encontra-se ainda dentro dos limites normais. Ainda, não está completamente estabelecido se a hipertensão arterial precede, é concomitante ou sucede ao desenvolvimento da microalbuminúria. Recentemente, demonstramos que na fase de microalbuminúria a pressão arterial de 24 horas é diferente daquela do diabético não microalbuminúrico. Assim, a pressão arterial noturna mostra-se mais elevada na fase de microalbuminúria, o que poderia estar predispondo à maior lesão renal. Nossos dados, também, sugerem um importante componente genético no desenvolvimento da microalbuminúria, uma vez que filhos de pais hipertensos apresentam maior excreção de albumina, quando comparados com filhos de pais normotensos, antes mesmo do aparecimento da mi- croalbuminúria. Finalmente, nossos achados recentes sugerem que a neuropatia circulatória ocorre, precocemente, no diabete tipo I e pode estar envolvida no aparecimento da albuminúria. Uma vez estabelecido o binômio microalbuminúria - hipertensão arterial, a progressão para insuficiência renal é inexorável. No entanto, o tratamento moderno com agentes anti-hipertensivos, especialmente os inibidores da ECA, retarda consideravelmente a progressão da lesão renal.

A resistência à ação da insulina é um fator constante na fisiopatogenia do diabete do tipo II. Paralelamente, tem-se demonstrado que a resistência à insulina é freqüentemente detectada, não somente no diabete tipo II, mas também em pacientes obesos e naqueles que apresentam hipertensão arterial, mesmo quando não obesos. A resistência à insulina promove hiperinsulinemia e hiperglicemia o que resulta em alterações lipídicas (aumento de triglicérides, diminuição do HDL colesterol e aumento do LDL colesterol) que favorecem o desenvolvimento da arteriosclerose. Por outro lado, a hiperinsulinemia pode ser "per si" um fator que favorece a elevação de níveis pressóricos por aumento do tônus simpático e da retenção renal de sódio. Além das implicações fisiopatogênicas, a hiperinsulinemia representa um importante referencial para o tratamento dos pacientes hipertensos, uma vez que ela pode ser agravada ou mesmo induzida por diuréticos e betabloqueadores. Em nossa experiência, os diuréticos induzem resistência à insulina, mesmo quando não induzem hipocalcemia. Bloqueadores de cálcio não agravam, e inibidores da enzima conversora, na realidade, diminuem a resistência a insulina.

\section{BIBLIOGRAFIA CONSULTADA}

1 - FERREIRA SRG et al. Blood pressure management in diabetic patients. Nefrologia 14: 267-271, 1994.

2 - ZANELLA MT et al. Blood pressure disturbances in diabetes mellitus. J Hypertens 10 (Suppl 7): S59-S70, 1992.

3 - ZANELLA MT et al. Hypokalemia, glucose intolerance and hyperinsulinemia during diuretic therapy. Hypertension 19: (supp II), 26-29, 1992. 


\section{ASPECTOS METABÓLICOS DA HIPERTENSÃO ARTERIAL - METABOLISMO DAS PURINAS}

\section{Celso Amodeo \\ Instituto Dante Pazzanese de Cardiologia - SP}

As purinas são algumas das bases nitrogenadas, utilizadas na formação dos nucleotídeos, que por sua vez são as estruturas de formação do DNA. Quando o DNA é degradado há a liberação de açúcares, grupos fosfato e bases nitrogenadas livres (purinas e pirimidinas). Uma das bases derivadas purínicas, a hipoxantina, sofre a ação da xantina oxidase e é transformada em xantina que, por sua vez, é transformada em ácido úrico. As bases nitrogenadas purínicas podem, também, ser de origem exógena.

A concentração de ácido úrico nos fluidos do organismo é resultante do balanço entre a taxa de produção e de excreção. Cerca de $2 / 3$ do ácido úrico é excretado na urina (300 a $600 \mathrm{mg} / \mathrm{dia}$ ), sendo o restante eliminado pelo trato gastrointestinal, onde é destruido pelas bactérias.

A hiperuricemia pode ser classificada como metabólica ou renal. Na forma metabólica, há um aumento na produção de ácido úrico; já, na forma renal, acontece uma diminuição na excreção. A hiperuricemia é, ainda, classificada como primária quando o aumento do ácido úrico é a manifestação central da doença. A hiperuricemia secundária refere-se aos casos que se desenvolvem durante o curso de outros processos mórbidos.

Do ponto de vista epidemiológico, a associação entre hiperuricemia e doença cardiovascular foi reportada há mais de um século por Huchard. Nos últimos 25 anos, muitos estudos têm correlacionado a gota e a hiperuricemia com o desenvolvimento de hiperlipidemia, diminuição da tolerância à glicose e hipertensão arterial. O estudo de Framingham demonstrou a correlação entre ácido úrico aumentado e hipertensão arterial. Entretanto o estudo Tecumseh foi inconclusivo em relação a tais aspectos. Hipertensão arterial e hiperuricemia coexistem em aproximadamente 25 a $35 \%$ dos pacientes, porém tais porcentagens variam entre os diferentes povos, sugerindo uma influência genética e, também, provavelmente do meio em que vivem (tal como o consumo de álcool). No estudo de Framingham, a incidência de coronariopatia foi o dobro em pacientes portadores de gota, quando os mesmos eram comparados com pares não gotosos (18\% versus 9.2\%). Tal incidência, também, foi alta em pacientes portadores de hiperuricemia assintomática.

Hiperuricemia é um fator de risco isolado para doença cardiovascular que embora esteja freqüentemente relacionado com obesidade, parece ter um efeito independente da obesidade. A morbi-mortalidade por doença aterosclerótica coronariana, hipertensão arterial aterosclerose periférica, e doença cerebrovascular aumentam progressivamente, de acordo com o aumento nas taxas de ácido úrico.

Pacientes com hipertensão arterial secundária a um quadro de gota apresentam como etiopatogênia da hipertensão arterial um dano renal resultante da precipitação de cristais de ácido úrico.

$\mathrm{Na}$ hipertensão arterial associada à hiperuricemia assintomática, a relação etiopatogênica da hipertensão é menos clara.

\section{REFERÊNCIAS RECOMENDADAS}

1 - HUCHARD H. Traité clinique des maladies du coeur et de l'aorte, G. Doin, Paris, 1899, p. 174.

2 - HALL AP. Correlations among hyperuricemia, hypercholesterolemia, coronary disease and hypertension. Arthritis Rheum, 8: 846-852, 1965.

3 - MYERS AR et al. The relationship of serumuric acid to risk factors in coronary heart disease. Am J Med, 45: 520-528, 1968.

4 - STRYER L, ed. Biochemistry. 3th ed. WH Freeman, New York,Chap. 25, 1988: Biosynthesis of nucleotides.

\section{PRESSÃO ARTERIAL E INGESTÃO DE LÍPIDES}

José Ernesto dos Santos

Professor Associado do Departamento de Clínica Médica do Hospital das Clínicas da Faculdade de Medicina de Ribeirão Preto da Universidade de São Paulo

A ingestão de ácidos graxos, em especial das famílias W-6 e W-3, parece influenciar os níveis de pressão arterial. Diversos estudos, tanto experimentais quanto clínicos sugerem que esses ácidos graxos, quando trocados na alimentação pelos ácidos graxos saturados reduzem a pressão arterial de ratos e humanos hipertensos.

Dois tipos de estudos vêm sendo conduzidos. Um primeiro tipo - os ácidos graxos são fornecidos 
sob a forma de alimentos. Em relação aos W-3, peixes têm sido utilizados. Esses estudos, embora em pequeno número, não demonstram efeito hipotensor dos ácidos graxos W-3. Com relação aos W-6, número maior de experimentos em unidades metabólicas, ou em intervenções em comunidades, com controle cuidadoso da ingestão, tem demonstrado efeito hipotensor.

Um outro tipo de modelo de estudo, utiliza os ácidos graxos sob a forma de cápsulas e em quantidades elevadas. Particularmente, acreditamos que esses estudos possam ser descritos como experimentos farmacológicos. Os estudos com W-6 são difíceis de serem interpretados, enquanto que os com W-3 sugerem seu potencial em reduzir os níveis de pressão arterial.

A produção de $\mathrm{PG}$ nos rins e em outros tecidos, a partir dos ácidos graxos poliinsaturados da dieta, pode ser um dos mecanismos envolvidos nesse efeito hipotensor. Até o momento, a medida dessa produção e o efeito dos W-6 e W-3 são extremamente difíceis.
Decididamente, somente técnicas mais aprimoradas de extração, cromatografia e espectroscopia de massa poderão permitir a análise acurada do efeito desses ácidos graxos na excreção urinária e na produção das PG.

Os níveis necessários de W-6 para reduzir os níveis de $\mathrm{P}$. A em hipertensos parecem ser de 5-10\%, o que está de acordo com as recomendações para reduzir os níveis séricos de lípides. A quantidade de $\mathrm{W}-3$ nos trabalhos publicados varia de 3 a $21 \mathrm{~g} / \mathrm{dia}$.

\section{BIBLIOGRAFIA CONSULTADA}

1. IACONO JM et al. Effect os dietary fat on blood pressure in a rural Finnish population. Am J Clin Nutr, 380: 860, 1983.

2. IACONO JM \& DOUGHERTY R. Effects os polynsaturated fats on blood pressure. Annu Rev Nutr, 13: 243, 1993.

3. DRISSING R et al. Effects of W-3 fatty acids on renal function and renal PGE - metabolism. Kidney Int 38: 315, 1990.

\section{ASPECTOS METABÓLICOS DA HIPERTENSÃO ARTERIAL - SÓDIO, POTÁSSIO, CÁLCIO, MAGNÉSIO}

\section{Mozart Regis Furtado}

Professor Titular Aposentado do Departamento de Clínica Médica do Hospital das Clínicas da Faculdade de Medicina de Ribeirão Preto da Universidade de São Paulo

Sódio - Falar sobre o sódio na gênese da hipertensão arterial (HA) é hoje um tema verdadeiramente bíblico no sentido de estar relacionado com os primórdios e com a evolução do conhecimento hipertensinogênico. Mais ainda, o Na é o “carrefour” dos inúmeros mecanismos conhecidos que explicam a elevação da pressão na HA: por isso é parte integrante de todo encontro sobre HA.

Durante anos, superestimou-se a participação do Na na hipertensinogênese ${ }^{(1)}$. Hoje, podemos dizer que o sal é apenas um do fatores que podem levar à elevação da PA naqueles indivíduos sensíveis (SS) à ação do $\mathrm{Na}^{2}$ e que constituem cerca de 20 a $50 \%$ da população hipertensa (valores não definidos ainda). Outra parcela de hipertensos, sal-resistentes (SR), é refratária à ação hipertensinogênica do $\mathrm{sal}^{2}$. O hipertenso SS tende a ser mais idoso, de raça negra, obeso (eventualmente diabético) e com renina plas- mática baixa. Ao contrário, o paciente SR é mais jovem, branco, hiper-reativo, com hiper-reninemia. O indivíduo SS é aquele que se beneficia com dieta sem sal e/ou diuréticos, bloqueador de cálcio, ou clonidina. $\mathrm{O}$ paciente $\mathrm{SR}$ responde bem à atividade física e a beta-bloqueador, ou então inibidor da enzima conversora da angiotensina (também clonidina).

Potássio - Ao contrário do $\mathrm{Na}$, que costuma participar em excesso no cardápio do homem acidental, o K, em geral, está presente em baixas quantidades. Esse desequilíbrio (iônico) dietético, forma a base racional da restrição alimentar de $\mathrm{Na}$ associada à elevada ingestão de $\mathrm{K}$ no tratamento nutricional da HA.

Aparentemente, a ingestão elevada de $\mathrm{K}$ deprime a atividade simpática, inibe a produção de renina - promovendo vasodilatação arterial e protege as artérias encefálicas de deposição aterosclerótica: assim, diminui a incidência de acidentes vasculares encefálicos ${ }^{3}$. Além desse efeito protetor de órgão-alvo, a administração de K é usada na correção de depleção de potássio que pode ocorrer durante tratamento com diuréticos (freqüentemente, associada à depleção de $\mathrm{Mg}$ ), com risco de arritmias ventriculares. 
Cálcio - Com base numa correlação inversa entre a ingestão dietética de Ca e os níveis de PA sistólica, observados num estudo populacional (NHANES I), McCarron levantou a hipótese de que a deficiência nutricional de Ca levaria a uma depleção do íon $\mathrm{Ca}$, ligado a membranas celulares. Como conseqüência, haveria desestabilização das membranas das células musculares lisas (dos vasos), levando a um aumento da reatividade arterial e elevação da resistência vascular periférica, responsável pela hipertensão ${ }^{4}$. Sugeriu-se, então, a suplementação dietética de Ca no tratamento da HA, mas os resultados até aqui têm-se mostrado inconsistentes e inconclusivos.

Magnésio - É um antagonista do Ca em muitos substratos, capaz de prender-se aos sítios de ligação do Ca na membrana celular, inibindo a corrente lenta de Ca para o interior da célula, à maneira dos bloqueadores de cálcio. Dessa forma, no músculo liso vascular, inibe a contratilidade e relaxa o vaso ${ }^{5}$. Apesar dessa ação vasodilatadora, a participação do $\mathrm{Mg}$ na gênese da HA não está definida.
Por outro lado, a hipomagnesemia tem sido relacionada ao aparecimento de arritmias cardíacas, principalmente quando acompanhada de hipopotassemia, situação não incomum em hipertensos, tratados com diuréticos e em diabéticos hipertensos.

\section{REFERÊNCIAS BIBLIOGRÁFICAS}

1 - DENTON D. The hunger for salt. Springer-Verlag, Berlin Heidelberg, 1984.

2 - CAMPESE V. Salt sensitivity in hypertension. Hypertension, 23: 531-550, 1994.

3 - TOBIAN L; JAHNER TM \& JOHNSON MA. High-K diets markedly reduce atherosclerotic cholesterol ester deposition in aortas of rats with hypercholes terolemia/hypertension. Am J Hypertens 3: 133-135, 1990.

4 - McCARRON DA; MORRIS CD \& COLE C. Dietary calcium in human hypertension. Science 217: 267-269, 1982.

5 - ALTURA BM \& ALTURA BT. Role of magnesium in the pathogenesis of hypertension. In: LARAGH JH \& BRENNER BM eds. Hypertension. Raven Press, New York, 1990, chapter 65.

\section{ENDOTÉLIO, ÓXIDO NÍTRICO E HIPERTENSÃO ARTERIAL}

Paulo Roberto B. Evora

Médico Assistente, Departamento de Cirurgia da Faculdade de Medicina de Ribeirão Preto da Universidade de São Paulo.

\section{Introdução ${ }^{1}$}

Em 1980, Furchgott demonstrou o relaxamento dependente do endotélio causado pela $\mathrm{ACH}$. Este fato abriu uma nova era de pesquisas sobre as moléstias cardiovasculares, propondo-se a existência de um fator relaxante endotelial, denominado EDRF por Cherry e Furchgott, em 1982. Até 1985, o único conceito definitivo era, apenas, que "o EDRF não era um prostanóide e era um elemento difusível”. Neste ano, Cocks e Angus foram capazes de obter culturas de células endoteliais tornando possível a manipulação bioquímica e farmacológica do EDRF. Nesta época, já havia um consenso de que a participação do endotélio na regulação do tono vascular sofria influência de neurotransmissores e de produtos plaquetários. Por analogia com os estudos de Ignarro e Murad sobre as ações dos nitrovasodilatadores, Furchgott e Ignarro propuseram, independentemente, que o "EDRF; era o óxido nítrico". Finalmente, o grupo do Dr. Moncada na Inglaterra provou que o EDRF era o óxido nítrico, sendo a sua fonte endógena a L-Arginina, sob a ação de uma óxido nítrico sintetase. Este grupo demonstrou, também, o bloqueio de síntese do óxido nítrico pela forma metilada da L-Arginina (L-NMMA).

A conclusão destas pesquisas foi a de que o EDRF/NO era um nitrovasodilatador e antiplaquetário endógeno, produzido pelo endotélio basalmente ou pelo estímulo de variados agonistas. O que havia de fantástico, nestas descobertas, era o fato de que pela primeira vez na história das ciências estava-se diante de um mediador que era um gás difusível e não um polipeptídeo vasoativo. Além disso, acumulam-se evidências de um papel orgânico universal do óxido nítrico, incluindo sua participação na fisiopatologia da hipertensão arterial.

\section{Regulação local do tono vascular ${ }^{1,2}$}

O endotélio libera importantes fatores, os quais exercem um importante papel na modulação do tono vascular, por meio de um efeito direto na musculatura lisa vascular. $\mathrm{O}$ mais importante destes fatores, o 
fator relaxante endotelial ("Endothelium-derived relaxing factor - EDRF), tem como seu componente ativo o óxido nítrico (NO), o qual atua como um nitrovasodilatador endógeno. Pela ativação da guanilato ciclase na musculatura lisa vascular, o EDRF/NO induz relaxamento, através de um mecanismo GMP-cíclico dependente. Um nível baixo de EDRF/NO é, continuamente, liberado pelo endotélio (liberação basal), o qual mantém um estado fisiológico de vasodilatação. Entretanto, a sua produção é, também, estimulada por "shear stress", neurotransmissores e produtos plaquetários. O EDRF/NO tem, também, outras funções vitais em adição aos seus efeitos vasodilatadores. Ressalta-se a inibição da adesividade e agregação plaquetárias, além de promover a desagregação plaquetária no vaso sanguíneo normal. Portanto, o EDRF/NO exerce um efeito antitrombótico e antivasoespástico na circulação. O endotélio, também, produz prostaciclina, a qual, como o óxido nítrico, relaxa a musculatura lisa vascular e inibe a agregação plaquetária. A prostaciclina ativa a adenilciclase, atuando através de mecanismos AMP-cíclico dependentes. Portanto, o EDRF/NO e a prostaciclina atuam através de diferentes mensageiros secundários. Entretanto, suas ações combinadas são sinergísticas. As células endoteliais são, também, capazes de produzir fatores contráteis como o ânion superóxido e o polipeptídeo vasoativo endotelina. Entretanto, o papel fisiológico e a importância destes fatores não são, ainda, bem conhecidos.

\section{As primeiras observações relacionando endotélio, EDRF/NO e hipertensão arterial ${ }^{3,4}$}

Como os fatores vasoativos, derivados do endotélio, exercem um profundo efeito sobre o tônus vascular e a resistência vascular periférica, é natural concluir-se que o comprometimento ou disfunção destes fatores podem contribuir para a fisiopatologia da hipertensão arterial. A disfunção endotelial que ocorre na hipertensão arterial é evidente, histologicamente, em vasos sanguiíneos hipertensos. $\mathrm{O}$ aumento da densidade de organelas citoplasmáticas e bandas microfilamentares associadas com um aumento no volume da célula endotelial são achados precoces na hipertensão. Enquanto um endotélio intacto é preservado, nota-se um aumento na razão de replicação associado a um aumento da permeabilidade da íntima e aumento da densidade da célula endotelial, durante os processos hipertensivos. Estas alterações morfológicas coincidem com as expressões dos relaxamentos e con- trações dependentes do endotélio. Observaram-se comprometimentos dos relaxamentos dependentes do endotélio na aorta, sob a ação da acetilcolina e ionóforo do cálcio A23187, e vasos de resistências em ratos, geneticamente, hipertensos, enquanto o relaxamento independente do endotélio ao nitroprussiato de sódio mostrava-se inalterado.

Existem evidências de que o comprometimento dos relaxamentos dependentes do endotélio sejam secundários à hipertensão e não uma etiologia desta:

a) o comprometimento destes relaxamentos pode ser obtido tornando hipertenso o animal normal de experimentação, e depois de revertido tornando normotenso o mesmo animal;

b) o grau de comprometimento está, diretamente, ligado ao grau de hipertensão, e

c) a disfunção endotelial pode ser revertida com a terapêutica anti-hipertensiva.

Este conceito é, amplamente, apoiado em dados obtidos em animais com coartação da aorta cirurgicamente induzida, nos quais a função endotelial encontra-se comprometida nos segmentos proximais hipertensivos e, mantém-se inalterada no segmento distal. Entretanto, Vanhoutte e colaboradores sugerem que o comprometimento dos relaxamentos dependentes do endotélio à acetilcolina, em aortas de ratos SHR, não se deve ao comprometimento da liberação de EDRF/NO, mas a uma concomitante produção de fatores contráteis derivados do endotélio (EDCFs). Acresça-se que as propriedades vasoativas, induzidas por agonistas em vasos hipertensos bioensaiados em musculatura lisa, foram comparáveis ao efluente de vasos normais, utilizados como controle. Determinou-se, também, que além de induzir a liberação de EDRF, a acetilcolina estimula a produção de um fator contrátil lábil dependente da via ciclooxigenase, possivelmente a prostaglandina $\mathrm{H} 2$.

Interessante, a contração ao estiramento dependente do endotélio encontra-se aumentada em vasos sangüíneos hipertensos, e a serotonina, que, normalmente, induz vasodilatação na circulação coronariana do rato, induz vasoconstrição em corações espontaneamente hipertensos. Esta resposta aberrante à serotonina é coincidente com a perda da inibição da contração dependente do endotélio, induzida por plaquetas agregadas na aorta destes animais. Em adição, o ânion superóxido produz um aumento na constrição da aorta de animais hipertensos que pode ser mediado através de um receptor da prostaglandina $\mathrm{H} 2$. 
Quando se avalia o papel da disfunção dependente do endotélio na hipertensão, é preciso levar em consideração que existem diferentes etiologias as quais podem se manifestar em padrões únicos de disfunção endotelial. Vanhoutte e colaboradores sugerem dois padrões da disfunção endotelial na hipertensão arterial, conforme as etiologias no modelo experimental, induzida por sal ou geneticamente induzida. Em ratos, espontaneamente, hipertensos, os relaxamentos dependentes do endotélio estão comprometidos pela concomitante produção de fatores relaxantes e contráteis. Já na hipertensão induzida por sal uma diminuição na produção do EDRF/NO parece estar relacionada com o comprometimento do relaxamento. A hipótese de que uma diminuição da produção de EDRF/NO relaciona-se com certos tipos de hipertensão é consistente com o achado do comprometimento in vivo da vasodilatação dependente do endotélio, produzida pela acetilcolina em membros superiores de humanos hipertensos. Em adição, o achado de que a endotelina induz hiperconstrição na artéria renal de ratos espontaneamente hipertensos, indica que peptídeos vasoativos produzidos pelo endotélio podem ter um papel no tônus vascular, aumentado na hipertensão arterial.

Para finalizar este resumo, alguns tópicos atuais relacionando endotélio, óxido nítrico e hipertensão arterial devem ser mencionados:

1) As variadas pesquisas nacionais e internacionais confirmam que, em condições fisiológicas, há predominância de fatores de inibição que desempenham papel protetor na circulação incluindo a agregação plaquetária. A disfunção endotelial, observada na hipertensão arterial, altera este delicado balanço passando a haver predomínio de fatores de contração e de promoção da proliferação celular.

2) A inibição prolongada da síntese de óxido nítrico é um modelo experimental de hipertensão arterial. Porém, existem os efeitos colaterais deste tipo de bloqueio, ressaltando-se que não existem observações em humanos.

3) Existem evidências da participação de radicais livres do oxigênio nos mecanismos da hipertensão arterial.

4) O magnésio é essencial em importantes processos intracelulares presentes na resposta endotelial e sua relação inversa com a hipertensão arterial. Existem comprovações, clínicas e experimentais, sobre os aspectos benéficos do magnésio sobre a aterosclerose, hiperlipidemias, arritmias e risco trombótico, tornando maior a sua importância, já que estes, freqüentemente, se associam à hipertensão arterial e condicionam maior risco cardiovascular.

5) Existem trabalhos, clínicos e experimentais, evidenciando um possível papel da L-arginina na reversão da disfunção endotelial na hipertensão arterial, bem como a sua repercussão favorável na hemodinâmica renal.

6) $\mathrm{O}$ grupo de drogas inibidoras da ECA, caracteriza-se pelo aumento da liberação da bradicinina que, por sua vez, estimula a liberação de NO ou de fator(es) relaxante(s) nítrico(s).

7) $\mathrm{O}$ recente desenvolvimento de uma nova classe de antiinflamatórios, os NO-NSAID (nitric oxide non steroidal antiinflamatory drugs), sugerem a possibilidade do desenvolvimento de novos fármacos anti-hipertensivos, baseados neste princípio (aclopamento do radical óxido nítrico às moléculas dos anti-hipertensivos clássicos). Esta associação poderia resultar em fármacos que apresentariam não somente atividade anti-hipertensiva como também permitiriam minimizar, desta maneira, possíveis disfunções endoteliais.

Estes dados podem ser estudados em detalhes em um número especial do HiperAtivo, correspondente à edição do segundo trimestre. Esta revista é o órgão oficial para as publicações do Departamento de Hipertensão da Sociedade Brasileira de Cardiologia. É recomendável, também, a leitura de recente artigo publicado por Francischetti et al. ${ }^{5}$ nos Arquivos Brasileiros de Cardiologia.

\section{REFERÊNCIAS BIBLIOGRÁFICAS}

1 - EVORA PRB. O impacto científico da descoberta do óxido nítrico como vasodilatador e antitrombótico endógeno (Editorial). Arq Bras Cardiol 61: 3-5, 1993.

2 - EVORA PRB; PEARSON PJ \& SCHAFF HV. Função endotelial e vasoespasmo coronariano após cirurgia cardíaca. Arq Bras Cardiol 61: 119-25, 1993.

3 - EVORA PR. Endotélio e hipertensão arterial. Do laboratório à pratica clínica. HiperAtivo. (Em publicação)

4 - EVORA PRB et al. "Aspectos históricos e fisiologia da função endotelial. Primeiras idéias relacionando o endotélio com a hipertensão arterial". HiperAtivo. (Em publicação)

5 - FRANCISCHETTI EA et al. Endotélio vascular. Um importante sistema cibernético vasomodelador e modulador cuja disfunção participa do processo hipertensivo. Arq Bras Cardiol 64: 53-68, 1995. 


\section{O ELETROCARDIOGRAMA NA HIPERTENSÃO ARTERIAL}

Paulo César B. Veiga Jardim

Prof. Adjunto da Faculdade de Medicina da Universidade Federal de Goiás. Coordenador da Liga de Hipertensão Arterial. Pós-Graduando (Doutorado) no INCOR da USP - Unidade de Hipertensão

O uso do eletrocardiograma está disseminado em todos os centros, é exame de fácil realização, tem baixo custo e permite uma boa sistematização na análise. Durante longo tempo, juntamente com o Raio-X de tórax, foi exame complementar exclusivo para detecção do comprometimento ventricular esquerdo na hipertensão arterial.

A presença de Hipertrofia Ventricular Esquerda foi associada a pior prognóstico (maior morbi-mortalidade) para o paciente hipertenso, a partir dos estudos epidemiológicos de Framinghan ${ }^{1}$. Definido o fato de que a hipertrofia ventricular esquerda representava fator de risco independente para morte de causa cardíaca, buscou-se ao longo do tempo melhorar os meios para o diagnóstico da HVE e os critérios de definição de HVE foram sendo ampliados.

Sabemos, hoje que o ECG tem baixa sensibilidade e alta especificidade na detecção da hipertrofia, quando comparado com o Ecocardiograma ${ }^{2}$. Desta maneira, o ECG nos permite, quando mostra alterações, definir claramente um paciente de alto risco. Ao contrário, quando o exame é negativo, ou seja não apresenta sinais de HVE não o exclui de um paciente de risco elevado pelo alto número de falsos negativos (baixa sensibilidade).

As clássicas alterações eletrocardiográficas da HVE são várias e representam um exagero do predomínio ventricular esquerdo, normalmente existente. $\mathrm{O}$ aumento dos potenciais do ventrículo esquerdo vai provocar aumento na voltagem dos complexos QRS. Ocorrerão ondas R, aumentadas nas derivações esquerdas e ondas $\mathrm{S}$, profundas nas derivações direitas (a explicação deste aumento passa não só pelo aumento da massa muscular, mas também pela interferência das pressões intraventriculares, volume de sangue intracavitário e atraso na despolarização ventricular, fazendo aparecer no traçado a ativação de uma porção isolada do QRS). O eixo de QRS tenderá a se orientar para a esquerda, para cima e para trás, apontando na direção do ventrículo dominante. Outro aspecto importante é o retardo na despolarização ventricular esquerda, provocando um retardo na deflexão intrinsicóide, este retardo, provavelmente, ocorre por ampliação da ativação dos feixes de Purkinje, além do aumento da massa. Haverá uma tendência progressiva a uma orientação de ST e T, na direção oposta ao QRS, podendo provocar o aparecimento de ondas $\mathrm{T}$ achatadas e/ou invertidas e desnivelamentos de ST no mesmo sentido. A desproporção entre massa muscular e leito vascular é um dos mecanismos que explica este fenômeno - ICo relativa; a repolarização, iniciada antes do término da despolarização, poderia explicar as alterações de ST.

Existem diversos critérios para o diagnóstico de HVE, alguns baseados em voltagem, como por exemplo SV1 + RV5 ou RV6 >35mm, que tem sensibilidade de $42.5 \%$ e excelente especificidade (95\%); maior onda $\mathrm{R}+$ maior onda $\mathrm{S}>45 \mathrm{~mm}$ (sensibilidade de $45 \%$ e especificidade de 93\%); SV1 ou V2 + RV5 ou V6 >35 mm que $55.5 \%$ e $88.5 \%$ de sensibilidade e especificidade, respectivamente. Romhilt and Estes sugeriram um critério de pontos para HVE. Por este critério, valem 3 pontos - $\mathrm{R}$ ou $\mathrm{S}$ nas derivações periféricas > $20 \mathrm{~mm}$; $\mathrm{S}$ em V1 ou V2 >30 mm ou R em V5 ou V6 $>30 \mathrm{~mm}$. Vale também 3 pontos o aumento de AE.As alterações de ST-T valem 3 pontos na ausência de digital e 1 ponto na presença deste. $\mathrm{O}$ desvio de eixo de QRS para a Esquerda (-30 graus ou mais) vale 2 pontos. A duração de $\mathrm{QRS}>=0.09 \mathrm{~s}$ ou a deflexão intrinsicóide em V5 ou V6 $>=0.05 \mathrm{~s}$ valem 1 ponto cada. Por este critério, quando se atinge 5 pontos a hipertrofia esquerda está presente, sendo o diagnóstico provável com a obtenção de 4 pontos. Este tipo de avaliação para a hipertrofia ventricular esquerda, também, deixa a desejar apresentando $54 \%$ de sensibilidade e $97 \%$ de especificidade ${ }^{3}$.

Apesar de todas as tentativas de melhorar a acurácia no diagnóstico da alteração ventricular esquerda, suas limitações são evidentes quando se compara com dados de necrópsia e com os obtidos por Ecocardiograma, o padrão ouro para este diagnóstico. A sensibilidade cresce nos casos com índice de massa ventricular maiores, sendo bastante baixa quando a massa ventricular é apenas levemente aumentada. 
Recentemente, Okin e colaboradores ${ }^{4}$ do grupo da Cornell, em Nova Iorque, publicaram estudo indicando que o produto da voltagem de QRS pela sua duração pode melhorar, significativamente, a sensibilidade do ECG na detecção da HVE, mantendo bons níveis de especificidade. Este método que, ainda, necessita maiores confirmações para validação pode ser incorporado à prática clínica e assim fortalecer a utilidade do ECG como método inicial e rotineiro na detecção da hipertrofia ventricular.

Vale ressaltar que, apesar das limitações do ECG na detecção da HVE, as facilidades na utilização do método (disseminação do uso, baixo custo e facilidade de sistematização de análise) continuam a manter o método como o de escolha para a avaliação inicial do paciente hipertenso ${ }^{5}$.

\section{REFERÊNCIAS BIBLIOGRÁFICAS}

1 - KANNEL WB; GORDON T \& OFFUTT D. Left ventricular hypertrophy by electrocardiogram: Prevalence, Incidende and: Mortality in the Framinghan Study. Ann Intern Med 71: 89-105, 1969.

2 - DEVEREUX RB et al. Methods for detection of left ventricular hypertrophy: Application to: Hypertensive heart disease. Eur Heart J 14 (suppl D), 8-15, 1993.

3 - ROMHILT DW et al. A critical appraisal of the electrocardiographic criteria for the diagnosis of left ventricular hypertrophy. Circulation 40:185-195, 1969.

4 - OKIN PM et al. Electrocardiographic identification of increased left ventricular: Mass by simple voltage-duration products. J Am Coll Cardiol 25: 417-423, 1995.

5 - KRAKOFF LR. Management of the hypertensive patient. Churchill Livingstone, New York, p. 51-74, 1995.

\section{O VALOR DO TESTE DE ESFORÇO NA AVALIAÇÃO DA HIPERTENSÃO ARTERIAL}

Renato B. P. de Castro

Médico Assistente, Divisão de Cardiologia do Departamento de Clínica Médica da Faculdade de Medicina de Ribeirão Preto da Universidade de São Paulo

O reconhecimento das vantagens da detecção precoce da Hipertensão Arterial Sistêmica (HAS) resultou na utilização de métodos diagnósticos suplementares. A avaliação da pressão arterial (PA) apenas em consultório, como realizada tradicionalmente, é insatisfatória dada a extrema variabilidade e baixa reprodutividade. Sabe-se que a PA eleva-se durante o esforço, paralelamente à carga desenvolvida, e que sua medida tem reprodutibilidade nitidamente maior. O teste de esforço (TE) configura-se, assim, como instrumental diagnóstico e de seguimento de grande valor nessa situação.

Analisaremos, inicialmente, a resposta fisiológica da PA durante o esforço e, a seguir, alguns aspectos diagnósticos e prognósticos.

Sabemos que a PA é função do débito cardíaco (DC) e da resistência vascular periférica (RVP). Exercícios envolvendo grandes grupos musculares, como o realizado durante o TE, causam vasodilatação nos territórios musculares que sobrepuja a vasoconstrição, observada em outros territórios (esplâncnico, renal), resultando em queda da RVP. O aumento da PA observado está, portanto, relacionado à elevação do DC, às custas da $\mathrm{FC}$ e do volume sistólico. $\mathrm{O}$ chamado "padrão normal" de elevação da PA durante o TE caracteriza-se por incremento dos valores sistólicos, pa- ralelamente à intensidade do esforço, e pela manutenção ou ligeira queda dos valores diastólicos. A magnitude do incremento sistólico em indivíduos normotensos tem seus valores normais definidos entre um mínimo de $10 \%$ sobre o valor basal e um máximo de $200 \mathrm{~mm}$ de $\mathrm{Hg}$, segundo alguns $\mathrm{s}^{1,2}$ ou $225 \mathrm{~mm} \mathrm{Hg}^{3}$.

A medida acurada da PA durante o esforço apresenta dificuldades de ordem técnica, notadamente em níveis de esforço mais intensos; embora aparelhos de medição automática tenham sido desenvolvidos, sua utilização sistemática no TE, ainda, não foi validada.

Respostas pressóricas exacerbadas durante o TE em indivíduos normotensos, em repouso, foram descritas como preditoras do desenvolvimento futuro de HAS $^{1}$. Wilson e Meyer ${ }^{3}$ acompanharam mais de 3.000 pacientes por 2,5 anos e encontraram uma "chance" duas vezes maior de desenvolvimento de HAS < naqueles com hiper-reatividade pressórica ao TE.

Uma correlação entre resposta da PA sistólica ao esforço e massa ventricular esquerda (avaliada pelo ecocardiograma bidimensional) foi detectada por Ren e col. ${ }^{4}$.

Frente às evidências expostas, a identificação de hiper-reatividade pressórica em indivíduos normotensos, em repouso, justifica uma abordagem preventiva (não medicamentosa) rigorosa, com controle dos fatores de risco evidenciáveis, tais como combate à obesidade, sedentarismo, tabagismo, restrição moderada da ingesta de sal, etc.

Nos pacientes portadores de HAS já instalada, podemos encontrar um padrão de resposta pressórica 
ao esforço de características normais. Ignora-se se isto refletiria um déficit inicial na capacidade de elevação do DC, durante esforço, ou seria atribuível a DC já elevado em condições basais.

Sheps e col. ${ }^{5}$ correlacionaram a elevação exagerada da PA diastólica ao esforço (maior que $15 \mathrm{~mm}$ $\mathrm{Hg}$ ) com doença arterial coronariana (DAC), mesmo na ausência de alterações do segmento S-T.

Indivíduos hipertensos, notadamente os portadores de hipertrofia ventricular esquerda, freqüentemente apresentam alterações de segmento $S$-T e onda $\mathrm{T}$ (padrão de "strain") dificultando a análise de alterações isquêmicas. Quando essas alterações basais são intensas, o TE convencional será de pouca valia para a detecção de DAC; o uso da cintilografia miocárdica com radioisótopos pode auxiliar o diagnóstico.

O uso do TE para avaliação de eficácia terapêutica na HAS tem sido analisado por diferentes autores ${ }^{6,7,8}$, embora não se constitua em indicação rotineira para oTE em nosso meio. Entretanto, a American Heart Association e American College of Cardiology reconhecem como principal indicação do TE no paciente hipertenso, avaliar a resposta da PA em indivíduos sob tratamento e que desejem realizar exercícios dinâmicos vigorosos.

\section{REFERÊNCIAS BIBLIOGRÁFICAS}

1 - DLIN RA et al. Follow-up of normotensive men with exagerated blood pressure response to exercise. Am Heart $\mathbf{J}$ 106: 316-320, 1983.

2. SCHRAGER BR \& ELLESTAD MH. The importance of blood measurement during exercise testing. Cardiovasc Rev Rep 4: 381-394, 1983.

3. WILSON NV; MEYER BM. Early prediction of hypertension using exercise blood pressure. Prev Med 10: 62-68, 1981.

4. REN JF; HAKKI AH \& KOTLER MN. Exercise systolic blood pressure: a powerfull determinant of increased left ventricular mass in patients with hypertension. J Am Coll Cardiol 5: 1224-1231, 1985.

5. SHEPS DS et al. Exercise induced increase in diastolic pressure: indicator of severe coronary disease. Am J Cardiol 43: 708, 1979.

6. CROW RS et al. Effect of antihypertensive medications on physical work capacity. J Cardiac Rehabil 4: 55, 1984.

7. GORDON NF et al. Comparision of captopril and conventional step 1 antihypertensive therapy: effects on exercise performance. J Cardiac Rehabil 8: 108, 1988.

8. RUTLEDGE JC et al. Efficacy of antihypertensive therapy at rest and during exercise. J Cardiac Rehabil 8: 116, 1988.

\section{PAPEL DA DOPPLER ECOCARDIOGRAFIA NA ABORDAGEM DE PACIENTES COM HIPERTENSÃO ARTERIAL SISTÊMICA}

Benedito Carlos Maciel

Professor Associado, Coordenador do Laboratório de Doppler Ecocardiografia - Divisão de Cardiologia do Departamento de Clínica Médica da Faculdade e Medicina de Ribeirão Preto da Universidade de São Paulo

A Doppler ecocardiografia constitui-se em técnica diagnóstica não invasiva de alta sensibilidade para identificar a existência de envolvimento cardíaco em pacientes com hipertensão arterial sistêmica. Aspectos variados da adaptação estrutural e funcional do ventrículo esquerdo à hipertensão podem ser abordados, adequadamente, com esta metodologia. Incluem-se: 1) a medida da espessura das paredes e a estimativa da massa ventricular que, analisadas relativamente às dimensões desta cavidade, permitem caracterizar a ocorrência ou não de hipertrofia, bem como seu padrão geométrico; 2) a avaliação da função diastólica ventricular esquerda, a partir da análise do padrão de enchimento ventricular, do tempo de relaxamento isovolumétrico e do fluxo de veias pulmonares; 3) a caracterização da função sistólica ventricular esquerda, mediante utilização de índices da fase de ejeção ventricular, como a percentagem de encurtamento sistólico da dimensão do VE, a Vcf e a fração de ejeção; 4) a estimativa do débito cardíaco e da resistência vascular sistêmica.

\section{Hipertrofia ventricular: diagnóstico e implicações}

A importância da identificação da hipertrofia ventricular esquerda em pacientes com hipertensão arterial sistêmica pode ser dimensionada pelas evidências inequívocas de que a sua ocorrência representa um importante preditor de risco para eventos cardiovasculares, independente dos níveis de pressão arterial e da idade ${ }^{1 / 3}$.

A avaliação quantitativa da massa ventricular esquerda, estimada pela ecocardiografia, quando cotejada com a espessura relativa da parede ventricular (2 x espessura diastólica da parede posterior do 
VE/ dimensão diastólica do VE) permite caracterizar três tipos de padrão geométrico ventricular ${ }^{4}$ : a) hipertrofia concêntrica (aumento da massa do VE associada a aumento da espessura relativa da parede ventricular); b) hipertrofia excêntrica (aumento da massa do VE em associação à uma espessura relativa da parede normal); c) remodelamento concêntrico (massa ventricular esquerda normal e aumento da espessura relativa da parede). Todas estas formas de adaptação podem ocorrer em pacientes hipertensos e expressam diferentes formas de sobrecarga hemodinâmica ${ }^{4,5}$. Assim, pacientes com hipertrofia concêntrica, que inclusive parecem apresentar pior prognóstico a longo pra$\mathrm{zo}^{2}$, geralmente, apresentam níveis elevados de resistência vascular sistêmica e débito cardíaco normal; enquanto naqueles com hipertrofia excêntrica documenta-se resistência vascular periférica normal ou reduzida em associação a volume plasmático e débito cardíaco elevados. No primeiro grupo, os níveis de pressão arterial sistêmica mostram-se elevados de modo persistente e importante durante monitorização ambulatorial da pressão, enquanto que, no segundo grupo, os níveis tensionais, geralmente, oscilam em torno dos limites superiores da normalidade. Por outro lado, em pacientes com padrão de remodelamento concêntrico, associam-se resistência vascular periférica elevada e níveis reduzidos de volume plasmático e débito cardíaco. A caracterização deste padrão geométrico ventricular, aliada a medidas da função sistólica ventricular esquerda, do débito cardíaco e da resistência vascular sistêmica, obtidos através da Doppler ecocardiografia, tornam possível estabelecer um perfil hemodinâmico de cada paciente hipertenso. A partir destas informações, é possível vislumbrar implicações para a indicação de tratamento farmacológico nestes pacientes. Infelizmente, até o presente, os estudos clínicos envolvendo terapêutica farmacológica não têm considerado, adequadamente, as particularidades hemodinâmico-geométricas destes diferentes grupos de pacientes hipertensos ${ }^{5}$, de modo que, a importância clínica da indicação terapêutica orientada, a partir deste perfil permanece por ser estabelecida em estudos sistematizados de longa duração ${ }^{6}$.

A indicação de estudo Doppler ecocardiográfico, em um paciente hipertenso, tem sido alvo de intenso debate em países desenvolvidos ${ }^{5 / 8}$ onde a relação custo-efetividade do procedimento vem sendo objeto de análise. A preocupação com os custos envolvidos na realização rotineira de um estudo Doppler ecocardiográfico completo, nesta população, resultou em uma proposta ${ }^{7}$ de apenas realizar um exame "limitado", de menor custo, direcionado para a avaliação da massa e do desempenho ventricular, além da medida da dimensão atrial esquerda. O custo-benefício desta abordagem limitada foi comparado, recentemente $^{8}$, com o de um estudo completo, que se mostrou essencial, ao adicionar informações diagnósticas relevantes, em apenas 5\% dos pacientes estudados. Assim, vem ganhando força, nestes países, o conceito de que um exame ecocardiográfico limitado pode representar uma estratégia com relação custo-benefício adequada na avaliação de pacientes hipertensos, reservando-se o estudo sistematizado completo para pacientes selecionados, com base nas suas características clínicas.

Considerando a elevada sensibilidade e especificidade da ecocardiografia para detecção de hipertrofia ventricular, parece razoável considerar que todos os pacientes que apresentem hipertensão arterial sistêmica persistente devam submeter-se a uma avaliação ecocardiográfica. Entretanto, o benefício clínico de tal política não está suficientemente fundamentado $^{5}$. Em algumas situações, a indicação para o estudo é bastante clara: 1) pacientes com cardiopatia concomitante (definida ou suspeitada); 2) na presença de hipertensão resistente à terapêutica, sem associação de envolvimento de outros órgãos-alvo; 3) pacientes com quadro clínico consistente, com cardiopatia hipertensiva. Em outras condições, o estudo pode ter benefícios potenciais ${ }^{5}$, como na presença de hipertensão leve persistente, não associada a fatores de risco cardiovasculares ou na presença de fatores modificáveis, quando o resultado do estudo pode orientar a indicação terapêutica (farmacológica ou não). Do mesmo modo, o exame pode ser indicado em pacientes com hipertensão, caracterizado como leve ou "borderline", que mostram níveis tensionais mais elevados, durante monitorização ambulatorial, uma vez que a pressão arterial avaliada por esta metodologia mostra uma boa correlação com a massa ventricular esquerda9 .

A freqüência com que o estudo Doppler ecocardiográfico deva ser repetido em pacientes hipertensos, também, não está estabelecida adequadamente. Tanto naquelas situações em que a hipertrofia foi bem documentada, como nos diferentes grupos de pacientes hipertensos em que isto não ocorreu, não parece haver benefício clínico em se repetir o exame antes de um ano ${ }^{5}$. Em qualquer caso, no entanto, a repetição deve ser julgada, criteriosamente, considerando a condição clínica de cada paciente, com o objetivo de buscar 
respostas a questões específicas, originadas desta avaliação. Ainda que a regressão da hipertrofia ventricular esteja bem demonstrada, como efeito de diversas medicações anti-hipertensivas, o valor prognóstico desta regressão não está, definitivamente, estabelecido ${ }^{10}$. Assim, a repetição do exame ecocardiográfico com o intuito de documentar este fenômeno é questionável.

A preocupação com os custos envolvidos na utilização ampla da ecocardiografia, como método de detecção de hipertrofia ventricular, justifica a posição da preferência pela eletrocardiografia. É uma técnica reconhecidamente muito menos sensível ${ }^{11}$, demonstrada pelo Joint National Committee on Detection, Evaluation, and Treatment of High Blood Pressure $(\mathrm{JNC} \mathrm{V})^{12}$ como método inicial de "screening", reservando-se a ecocardiografia para casos selecionados.

Algumas considerações de ordem técnica são importantes relativamente à caracterização da hipertrofia ventricular, a partir da determinação da massa ventricular esquerda pela ecocardiografia. Estudos de qualidade suficiente para permitir a estimativa da massa são obtidos em $80-90 \%$ dos pacientes avalia$\operatorname{dos}^{6,8}$. A qualidade do estudo, no entanto, não depende apenas da existência de uma janela ecocardiográfica adequada. Exatamente por tratar-se de um método de diagnóstico por imagem, a confiabilidade das medidas obtidas dependerá diretamente da experiência do examinador, do cuidado na execução do estudo, da existência de critérios bem definidos para obtenção dos dados, bem como da consciência tanto do potencial, quanto das limitações do método aplicado. Esta preocupação é fundamental quando se considera que decisões terapêuticas podem ser tomadas com base neste procedimento.

Assim, é crucial que o clínico que utiliza a ecocardiografia na avaliação dos pacientes com hipertensão arterial sistêmica conheça os princípios básicos que possibilitem estimar a massa ventricular esquerda por esta técnica. Todos os métodos descritos partem do pressuposto básico de que o volume do músculo cardíaco é igual à diferença entre o volume cardíaco (limitado pelo epicárdio) e o volume da cavidade ventricular. A massa ventricular pode, então, ser obtida pelo produto: volume x densidade do músculo cardíaco. Os vários métodos disponíveis para estimar o volume cardíaco assumem que o coração tenha uma determinada forma geométrica (ou a associação de formas geométricas), conduzindo ao uso de fórmulas mais ou menos complexas para este cálculo. O uso clínico de um método de estimar o volume dependerá da sim- plicidade da sua execução. Exatamente por isso é que o método do cubo, que assume o ventrículo esquerdo como um elipsóide de revolução, com uma razão de 2:1 entre os comprimentos do seu eixo maior e menor, tornou-se o mais utilizado. Não se pode ignorar, no entanto, que esta é uma grande simplificação que pode limitar a precisão da estimativa. Deste modo, várias tentativas de corrigir as limitações deste cálculo foram empreendidas em estudos sucessivos, sendo que aquela que calcula a massa do VE como $=0,8 \times 1,04$ [(dimensão diastólica do VE + espessura do septo ventricular + espessura da parede posterior $)^{3}$ - (dimensão diastólica do $\left.\mathrm{VE})^{3}\right]+0,6$ é uma das mais freqüentemente utilizados no contexto clínico ${ }^{13}$. Como consequiência, valores normais diferentes têm sido relatados nos diversos estudos. Deste modo, o critério de hipertrofia ventricular não é homogêneo na literatura. Considerando que a massa ventricular depende do sexo e das características antropométricas do indivíduo, os limites da normalidade estabelecidos, geralmente, consideram o sexo, a superfície corporal ou a altura. Assim, no estudo de Deveraux ${ }^{13}$ o limite superior do normal foi de $134 \mathrm{~g} / \mathrm{m}^{2}$ para homens e $110 \mathrm{~g} / \mathrm{m}^{2}$ para mulheres, sendo que no estudo de Framingham ${ }^{14}$ os limites superiores foram, respectivamente, de 131 e $100 \mathrm{~g} / \mathrm{m}^{2}$. Deve-se ter presente as limitações destes valores, quando se considera pacientes com obesidade.

\section{Função sistólica e diastólica do ventrículo esquerdo}

Com exceção das fases mais avançadas da doença, os índices do desempenho sistólico da fase de ejeção, obtidos pela ecocardiografia, apresentam-se dentro dos limites da normalidade em pacientes hipertensos. Estes índices, como o $\Delta \mathrm{D} \%$, o VCf e a fração de ejeção, podem até, na fase inicial da hipertensão, apresentar valores "supra-normais". Na fase avançada da doença, contudo, a hipertrofia pode se tornar insuficiente para compensar o aumento do "estresse" da parede ventricular, quando, então, a função sistólica tende a deteriorar-se.

A função diastólica pode alterar-se, precocemente, na história natural da hipertensão. Potencialmente, a Doppler ecocardiografia é capaz de identificar a disfunção diastólica com base no padrão de enchimento diastólico do VE, na medida do tempo de relaxamento isovolumétrico e no padrão de fluxo de veias pulmonares. No entanto, a sensibilidade desta técnica não está definida em pacientes com hipertensão arterial. Em estudo recente ${ }^{8}$, a técnica de Doppler não adicionou informação clinicamente relevante em 
um grupo de pacientes hipertensos, sem complicações, submetidos a um exame de rotina.

Em resumo, a avaliação Doppler ecocardiográfica de pacientes hipertensos pode adicionar informações substanciais para caracterizar o envolvimento cardíaco nesta condição clínica, bem como para orientar a decisão terapêutica. Deve-se considerar na indicação do exame o benefício potencial dele resultante, em confronto com os custos inerentes ao procedimento.

\section{REFERÊNCIAS BIBLIOGRÁFICAS}

1 - CASALE PN et al. Value of echocardiographic measurement of left ventricular mass in predicting cardiovascular morbid events in hypertensive men. Ann Intern Med 105: 173-178, 1986.

2 - KOREN MJ et al. Relation of left ventricular mass and geometry to morbidity and mortality in uncomplicated essential hypertension. Ann Intern Med 114: 345-352, 1991.

3 - LEVY D et al. Prognostic implications of echocardiographically determined left ventricular mass in the Framingham Heart Study. N Engl J Med 322: 1561-1566, 1990.

4 - GANAU A et al. Patterns of left ventricular hypertrophy and geometric remodeling in essencial hypertension. J Am Coll Cardiol 19: 1550-1558, 1992.

5 - DE SIMONE G et al. Echocardiography in arterial hypertension: when, why and how? J Hypertens 12: 1129-1336, 1994.
6 - DUNN F G \& PRINGLE S D. Echocaardiography in arterial hypertension: when, why and how? J Hypertens 12: 1137-1138, 1996.

7 - BLACK HR; WELTIN G \& JAFFE CC. The limited echocardiogram: a modification of standard echocardiography for use in the routine evaluation of patients with systemic hypertension (editorial). Am J Cardiol 67: 1027-1030, 1991.

8 - SHUB C; TAJIK J \& SHEPS S G. The value of two-dimensional echocardiography and Doppler examination in the assessment of hypertensive patients. A pilot study. J Am Soc Echocardiogr 8: 280-284, 1995.

9 - DRAYER JIM; WEBER MA \& DE YOUNG JL. BP as a determinant of cardiac left ventricular mass. Arch Int Med 143: 90, 1983.

10 - LEBSON PR. Clinical studies of drug reversal of hypertensive left ventricular hypertrophy. Am J Hypertens 3: $512,1990$.

11 - DEVEREUX RB et al. Methods for detection of left ventricular hypertrophy: application to hypertensive heart disease. Eur Heart J 14 (suppl D): 8-15, 1993.

12 - THE JOINT NATIONAL COMMITEE ON DETECTION. Evaluation, and Treatment of High Blood Pressure: Thefifth report. Arch Intern Med 153: 154-183, 1993.

13 - DEVEREUX R B et al. Echocardiographic assessment of left ventricular hypertrophy: comparison to necropsy findings. Am J Cardiol 57: 450-458, 1986.

14 - LEVY D. Echocardiographic criteria for left ventricular hypertrophy: the Framingham Heart Study. Am J Cardiol 59: 956-960, 1987.

\section{AVALIAÇÃO ULTRA-SONOGRÁFICA DO SISTEMA VASCULAR EM PACIENTES HIPERTENSOS}

\section{Sérgio Ajzen}

Professor Adjunto, Doutor em Radiologia do Departamento de Diagnóstico por Imagem da Escola Paulista de Medicina da Universidade Federal de São Paulo

A avaliação clássica do sistema vascular, no estudo de grandes vasos, só era possível através de autópsias. No que concerne a pequenos e médios vasos, esta avaliação pode ser realizada por biópsias de pele, músculos e outros órgãos que nos permitem acesso.

A ultra-sonografia e o seu avanço tecnológico permitem, atualmente, uma visibilização direta dos vasos de médio e grande calibre, possibilitando informações em tempo real, tanto da luz como da parede do vaso, na ordem de frações de milímetro. Assim, é possível monitorar o comprometimento dos grandes vasos, in vivo, ao longo do tempo e, com isto, avaliar as alterações estruturais dos mesmos na história natural do processo hipertensivo.

Neste sentido, corroborando as observações da anatomia patológica, tem-se observado que as alterações encontradas nos vasos, na hipertensão arterial, em muito se assemelham àquelas que ocorrem com a idade. Esta similaridade entre lesão do vaso na hipertensão e lesão vascular própria do envelhecimento foi, particularmente, documentada em modelos experimentais de hipertensão. Atualmente, com a disponibilidade de aparelhos de ultra-sonografia, que permitem avaliar com precisão os vasos, começam a surgir observações em seres humanos que comprovam a similaridade entre lesões vasculares, decorrentes da hipertensão e aquelas próprias do envelhecimento.

Nesta apresentação, iremos demonstrar as lesões vasculares da hipertensão, assim como as observadas em indivíduos idosos. 


\section{MONITORIZAÇÃO AMBULATORIAL DA PRESSÃO ARTERIAL}

\section{Fernando Nobre}

Divisão de Cardiologia da Unidade de Hipertensão. Hospital das Clínicas da Faculdade de Medicina de Ribeirão Preto da Universidade de São Paulo

Monitorização Ambulatorial da Pressão Arterial (MAPA) é uma técnica através da qual medidas múltiplas e indiretas da pressão arterial podem ser obtidas durante 24 ou mais horas consecutivas, com um mínimo de desconforto, durante as atividades diárias do paciente ${ }^{1}$.

A possibilidade de se obter uma curva representativa das variações pressóricas, em determinado período, faz com que se possa ter uma visão dinâmica do comportamento tensional e não apenas uma observação meramente estática, refletindo somente o instante em que foi medida a pressão arterial $^{2}$.

A utilização da MAPA permite-nos estudar o padrão normal de pressão arterial ${ }^{3,4}$, as lesões em órgãos alvos decorrentes da hipertensão ${ }^{5}$, o prognóstico de eventos cardiovasculares e mortalidade ${ }^{6,7}$ e a análise da eficácia das drogas anti-hipertensivas ${ }^{8,9,10}$.

Por outro lado, a MAPA, é hoje um procedimento, efetivamente, incorporado à prática cardiológica.

Em 1987, Garret e Kaplan ${ }^{11}$ em editorial do Journal of Clinic Hypertension, colocavam a MAPA como um procedimento promissor e cheio de ótimas perspectivas nas suas aplicações. Recentemente, o Board of Trusttees of The American College of Cardiology aprovou parecer de uma comissão de renomados especialistas em hipertensão, sob o título "ACC Position Statement - Ambulatory Blood Pressure Monitoring ${ }^{12}$ que, em resumo, conclui: "A MAPA tornou-se um método maduro, clinicamente aplicável, com normatizações desenvolvidas por importantes sociedades e com consensos americanos e internacionais para suas indicações e procedimentos."

\section{VANTAGENS, LIMITAÇÕES E PRINCIPAIS INDICAÇÕES}

As principais vantagens e as limitações da monitorização ambulatorial, em relação às medidas casuais da pressão arterial, são mostradas na Tabela I.
Tabela I: Monitorização ambulatorial da pressão arterial: vantagens e limitações ${ }^{1}$

VANTAGENS

- Obtenção de múltiplas medidas

- Medidas durante as atividades usuais do paciente

- Ausência ou redução da reação de alerta

- Medidas durante o sono

- Ajuste dos intervalos de medidas

- Correlação com eventos ocorridos durante o exame

- Avaliação do ritmo circadiano da PA e freqüência cardíaca

- Possibidade de análise de grande número de dados

\section{LIMITAÇÕES}

- Perdas de dados (falhas técnicas)

- Distúrbios no trabalho e no sono

- Limitação de normalização de dados

- Falta de adequada avaliação dos equipamentos

- Alto custo

- Desconforto

Situações clínicas onde a MAPA tem utilidade e, portanto, indicação, estão expressas naTabela II.

Tabela II: Principais indicações da monitorização ambulatorial da PA(1)

- Hipertensão "borderline" com lesão de órgãos alvos

- Hipertensão do avental branco (hipertensão de consultório)

- Avaliação das hipertensões resistentes ao tratamento

- Hipertensões episódicas (e.g. feocromocitoma

- Síncopes

- Hipotensões sintomáticas associadas a medicamentos anti-hipertensivos

- Disfunções autonômicas

- Avaliação do comportamento pressórico na angina noturna e na congestão pulmonar

- Avaliação da eficácia terapêutica 


\section{UTILIZAÇÃO DA “MAPA" NA PRÁTICA CLÍNICA}

\section{Hipertensão "borderline" e presença de lesões em ór- gãos alvos}

Ocasionalmente, indivíduos que apresentam pressões do tipo "normal alto" (valores entre 85 a $89 \mathrm{mmHg}$ ) e que têm lesões em órgãos alvos (e. g. hipertrofia ventricular esquerda, retinopatia, etc) podem, quando submetidos à MAPA, mostrar níveis de PA, significativamente, mais elevados relacionados a "estresse", esforço físico e/ou mental, tipo de trabalho, evidenciando que, nestes casos, a PA obtida no consultório foi subestimada.

\section{Hipertensão do avental branco ou hipertensão do con- sultório}

Pickering e O'Brien ${ }^{13}$ afirmam, categoricamente, que a mais importante das aplicações clínicas da MAPA consiste na possibilidade de avaliar, adequadamente, os pacientes que apresentam um comportamento anormal da PA, quando examinados no consultório, mas não o reproduzem na observação de 24 horas. Krakoff e cols. ${ }^{14}$ estimam que o número de pacientes com hipertensão leve, em tratamento medicamentoso anti-hipertensivo, poderia ser reduzido para em torno de $75 \%$, sem que a mortalidade aumentasse.

Nós, também, não temos dúvidas de que esta possibilidade atraente e prática de se excluir um contingente aproximado de 20 a $40 \%$ dos hipertensos leves e moderados, qualifica a MAPA como método dos mais úteis para este fim.

Alguns estudos sugerem ${ }^{15,16}$ que grande parte destes pacientes que tem pressão arterial alterada no consultório, mas tem curvas de pressão de 24 horas normais não precisam ser tratados, porque não reproduzem, em sua atividades habituais, o mesmo comportamento tensional, observado frente ao médico.

Durante o último Congresso Mundial de Hipertensão, realizado em Melbourne, Austrália, vários trabalhos, ainda não publicados, mostraram que estes pacientes apresentam maior probabilidade de complicações decorrentes da hipertensão arterial, dentre elas, alterações mais freqüentes de órgãos alvos.

Estes aspectos, ainda por resolver, deverão ser motivo de estudos prospectivos de grande escala para que tenhamos as respostas necessárias.

\section{Hipertensão resistente à terapêutica}

Considera-se que a hipertensão é resistente ao tratamento quando não há resposta adequada pelas avaliações de consultório, em um paciente submetido à tríplice terapia. Entretanto, muitas vezes o efeito "Avental Branco" é o responsável por esta inadequada resposta hipotensora. Se há indícios de que a PA está controlada, por exemplo através de avaliações domiciliares, a MAPA está indicada para a análise da eficácia da medicação em uso. Há, também, de se considerar as características individuais de cada paciente frente à ação dos medicamentos que estão sendo utilizados, fato no qual a monitorização da pressão arterial pode colaborar de maneira importante.

\section{Hipertensões episódicas}

A situação mais freqüente que retrata episódios isolados de hipertensão é a ocorrência do feocromocitoma. Ainda, podemos observar picos hipertensivos em pacientes com síndrome de ansiedade ou de outras formas de desordens psíquicas. Em geral como forma de diferenciação, não absoluta, mais possível, entre as duas situações está a ausência de descenso da pressão durante o sono, muito comum nas hipertensões secundárias. Temos, também, que lembrar a ausência de elevações ocasionais da PA, em boa parte dos pacientes portadores deste tumor secretor de catecolaminas, bem como a "normalidade " pressórica observada em alguns deles.

\section{Síncopes e hipotensões sintomáticas}

A ocorrência de episódios de hipotensões, induzidas por medicamentos ou mesmo de síncopes pode, perfeitamente, ser detectada pela MAPA em 24 horas, enquanto que dificilmente poderia ser observada nas avaliações casuais.

\section{Avaliação da eficácia terapêutica anti-hipertensiva}

Muito tem se estudado ${ }^{17,18,19}$ nos últimos anos a respeito da utilidade da MAPA na avaliação da eficácia terapêutica das drogas anti-hipertensivas. Recentes publicações ${ }^{20,21,22}$ a respeito da variação pressórica nas 24 horas, bem como a análise da eficácia das principais medicações, utilizadas no tratamento da hipertensão, tem demonstrado a importância destes aspectos no prognóstico dos pacientes hipertensos. Nós mesmos utilizamos a monitorização ambulatorial da 
MAPA em algumas investigações ${ }^{23,}{ }^{24}$ com medicamentos anti-hipertensivos, objetivando a análise de sua eficácia terapêutica.

\section{Considerações finais}

A MAPA é um procedimento que, efetivamente, incorporou-se à nossa atividade clínica. A cada dia, maiores são os benefícios que podem ser auferidos desta fascinante metodologia. A crescente publicação de novas informações, estudos prospectivos em andamento, a maior difusão do método e conseqüentemente o melhor conhecimento a seu respeito, farão com que tenhamos, num futuro muito próximo, uma visão muito mais adequada e judiciosa deste importante método.

O caminho do melhor conhecimento da hipertensão arterial, a respeito de sua fisiopatologia, diagnóstico, terapêutica e prognóstico, é seguramente constituído pelo entendimento das variações dinâmicas da pressão arterial, adequadamente estudadas pela Monitorização Ambulatorial da Pressão Arterial de 24 horas.

\section{REFERÊNCIAS BIBLIOGRÁFICAS}

1 - NATIONAL HIGH BLOOD PRESSURE EDUCATION PROGRAM WORKING GROUP. Report on Ambulatory Blood Pressure Monitoring. Arch Intern Med 150: 2270-2280, 1990.

2 - ELLIOT HL. Annals of II International Nifedipine GITS Symposium. Paris, p. 17-20, 1994.

3 - MILLAR-CRAIG M W; HAVES D E \& WHITTINGTON J. New system for recording ambulatory and blood pressure in man. Med Biol Eng Comput 16: 727-731, 1978.

4 - NOBRE F et al. Consenso Brasileiro para o uso monitorização ambulatorial da pressão arterial. Arq Bras Cardiol 60: 129-134, 1993.

5 - SOKOLOW M et al. Relationship between levels of blood pressure casually and by portable recorders and severity of complications in essential hypertension. Circulation 34: 279-298, 1966.

6 - PERLOFF D; SOKOLOW M \& COWAN R. The prognostic value of ambulatory blood pressure monitoring in treated hypertensive patients. J Hypertens 9 (suppl 1):S33-40, 1991.

7 - PICKERING TG \& DEVEREUX RB. Ambulatory monitoring of blood pressure as a predictor of cardiovascular risk. Am Heart J 114: 925-928, 1987.

8 - WHITE WB. Analysis of ambulatory blood pressure data antihypertensive drug triais. J Hypertens 9 (suppl 1): S27-32, 1991.
9 - WHITE WB \& MORGANROTH J. Usefulness of ambulatory blood pressure monitoring in assessing antihypoertensive therapy. Am J Cardiol 63: 94-98, 1989.

10 - NOBRE F \& NOGUEIRA JL. Tratamento da hipertensão arterial sistêmica com urapidil. Estudo na hipertensão leve e moderada com monitorização ambulatorial da pressão arterial. Arq Bras Cardiol 61: 63-68, 1993.

11 - GARRET NB \& KAPLAN N. Ambulatory blood pressure monitoring. A question for now and the future. J Clin Hypertens 3: 378-380, 1987.

12 - SHEPS SG et al. ACC postion statement: Ambulatory Blood Pressure Monitoring. J Am Coll Cardiol 23: 1511-1513,1994.

13 - SECOND INTERNATIONAL CONSENSUS Meeting on 14 hour blood pressure ambulatory monitoring measurement: consensus and conclusions. J Hypertens 9 (suppl 8): S2-26, 1991.

14 - SECOND INTERNATIONAL CONSENSUS Meeting on 24 hour blood pressure ambulatory monitoring measurement: consensus and convulsions. J Hypertens 9 (suppl 8): S28-30, 1991.

15 - PICKERING TT \& JAMES JD. Some implications of the diferences between home, clinic and ambulatory blood pressure in normotensive patients. J Hypertens 7 (suppl 3) S65-72, 1989.

16 - WHITE WB. Average daily blood pressure, not office blood pressure, determines cardiac function in patients with hypertension. JAMA 261: 873-877, 1989.

17 - ELLIOT JHL. Trough: Peak ratio and twenty-four-hour blood pressure control. J Hypertens 12 (suppl 5): S29-33, 1994.

18 - MEREDITH PA. Trough: Peak ratios for antihypertensive agents. The issues en perspective. Drugs 48: 661-666, 1994

19 - PARATI G et al. Blood pressure variability: clinical implications and effects of antihypertensive treatment. J Hypertens 12 (suppl 5): S35-40, 1994

20 - PARATI G et al. Blood pressure variability: clinical implications and effects of antihypertensive treatement. J Hypertens 12 (suppl 5): 35-40, 1994.

21 - COCA A. Circadian rhythm and blood pressure control: physiological and pathophysiological factors. J Hypertens 12 (suppl 5): S13-21, 1994.

22 - COLIN JS; VALENTE AJ \& HILDEBRANDT. Prevention of atherosclerosis and end-organ damage: a basis for antihypertensive interventional strategies. J Hypertens 12 (suppl 5): S-3-11, 1994.

23 - NOBRE F \& OIGMAN W. Avaliação da eficácia terapêutica de Diltiazen AP no tratamento da hipertensão leve e moderada, com monitorização ambulatorial da pressão arterial Arq Bras Cardiol 63: 321-326, 1994.

24 - MAGLIANO MF et al. Estudo multicêntrico brasileiro de avaliação da eficácia e tolerabilidade da isradipina SRO, através de monitorização ambulatorial da pressão arterial no tratamento da hipertensão arterial leve e moderada. Arq Bras Cardiol 61: 311-318, 1993. 


\section{TRATAMENTO NÃO MEDICAMENTOSO DA HIPERTENSÃO: OBESIDADES}

José Ernesto dos Santos

Professor Associado do Departamento de Clínica Médica do Hospital das Clínicas da Faculdade de Medicina de Ribeirão Preto da Universidade de São Paulo

\section{Obesidade: prevalência diagnóstico}

As Obesidades têm alta prevalência no Brasil. Estima-se que cerca de $25 \%$ da população, ou seja próximo de 36.000.000 de brasileiros, apresentem algum grau de excesso de peso. É, também, motivo de frustração para o paciente e para o terapeuta, visto que, quando avaliado sob diferentes ângulos, o resultado do tratamento é adequado somente para uma porcentagem pequena de pacientes.

O diagnóstico e a quantificação do grau de obesidade é um problema não resolvido. Em indivíduos com grau significativo de adiposidade, o diagnóstico é visual. Contudo, em situações menos graves e também, como temos necessidade de quantificar o grau, bem como definir objetivos a serem alcançados no tratamento, buscamos valores de referência que sirvam para esses fins. São usados pelo menos três critérios.

1. Tabela de peso desejável: usa-se em geral tabelas americanas, obtidas da National Health an Nutrition Examination Surveys (NHANES) ${ }^{1}$. Essas, são originadas do acompanhamento de grupos populacionais americanos e compiladas em percentis para o peso, a idade e o sexo. Usualmente, "excesso de peso" é definido como acima de percentil 85. Por não levarem em consideração nenhum risco à saúde, os números somente descrevem a distribuição ponderal da população. Pela inexistência de uma população-referência (com baixa prevalência de doenças causadas ou associadas à obesidade), seu uso torna-se muito discutido, tanto no país onde elas foram construídas, como, e muito mais, em outros.

2. Tabelas do peso ideal: São tabelas desenvolvidas pela Metropolitan Life Insurance Company. Nestas, são referidos intervalos de peso, nos quais é menor a morbidade e maior a longevidade. A última tabela, publicada em 1983, representou a análise dos resultados observados por 25 companhias de seguro dos EUA e Canadá ${ }^{2}$. Além das dificuldades de sua adoção em outros países, nos próprios países onde foram formuladas, são feitas críticas quanto aos seguintes aspectos: a) os indivíduos segurados não representam amostragem de população tomada ao acaso; b) esses indivíduos são "selecionados" pelo estado de saúde, conseqüentemente representam a população mais saudável; c) levam em consideração três graus de compleição física (pequeno, médio e grande), que são medidas de definição imprecisa; d) cerca de $20 \%$ dos indivíduos que constam dessas tabelas tiveram seus pesos e altura referidos e não pesados e medidos.

3. Índice de massa corporal (IMC): É definido como peso (em quilogramas), dividido pelo quadrado da altura (em metros). O acompanhamento de populações evidência que o IMC, onde é menor a prevalência de doenças e mortes, é $22,3 \mathrm{~kg} / \mathrm{m}^{2}$ para homens e $22,5 \mathrm{~kg} / \mathrm{m}^{2}$ para mulheres. Embora seja atualmente o índice mais utilizado em clínica, algumas críticas, também, podem ser feitas, especialmente quanto à evolução do IMC com a idade. Sabe-se que o envelhecimento é um processo que aumenta a adiposidade, muitas vezes sem variação de peso. Para as mulheres, aos 25 anos a porcentagem de gordura corporal é, em média, 27,8. Essa porcentagem aumenta de tal maneira que aos 65 anos ela representa $34,1 \%$ do peso corporal. Para os homens esse valores aumentam de $20,9 \%$ para $28,4 \%$ nas mesmas faixas etárias ${ }^{3}$. Uma vantagem do IMC, como definitivo de obesidade, é a possibilidade de gradação. Em geral, define-se como grau I - índices de 25-29,9; grau II - índices de 30-40 e grau III - valores acima de $40 \mathrm{~kg} / \mathrm{m}^{2}$.

4. Outros métodos vêm sendo utilizados, menos em prática clínica e mais em pesquisa, com potencial, no entanto, para suas aplicações em futuro não muito distante. Assim, a impedância bioelétrica, as medidas de composição corporal com água tritiada e a tomografia computadorizada são métodos que avaliam a composição corporal e a distribuição de gordura. Além desses, utilizados de há muito, as medidas das pregas cutâneas representam, também, método útil e sensível na avaliação do grau de obesidade.

As medidas das pregas subescapulares, tricipital, suprailíaca e triciptal podem, em conjunto, fornecer dados importantes na avaliação e no tratamento de obesos. 


\section{Obesidade e o risco de doença cardiovascular}

A prevalência de hipertensão arterial (definida como valores acima de 160/95 mmHg) é, aproximadamente, três vezes maior em obesos do que em indivíduos com pesos situados na faixa de normalidade. Diversos estudos, como o de Framingham, demonstram que a prevalência de hipertensão é dez vezes maior em indivíduos com $20 \%$ ou mais de peso desejável do que em controles ${ }^{4}$. Em pessoas obesas, ocorre aumento da volemia e do volume ventricular residual diastólico, que resulta em aumento do volume minuto cardíaco. A dilatação e a hipertrofia ventricular esquerda podem ser resultantes desses processos. Como consequiência, os obesos hipertensos têm maior propensão à insuficiência cardíaca e morte súbita.

Outros riscos cardiovasculares freqüentemente associados à obesidade são as alterações dos padrões de lipoproteínas séricas. Os níveis de HDL apresentam-se freqüentemente diminuídos e os valores de LDL podem estar elevados. A hipertrigliceridemia é um sinal bioquímico muito prevalente entre obesos, sendo que essa alteração é consequiente a modificações no metabolismo das pré-beta lipoproteínas. É mais prevalente em obesos que apresentam intolerância à glicose ou níveis glicêmicos de jejum elevados. $\mathrm{O}$ aumento na produção de VLDL é, provavelmente, a sua causa principal. É um tema atual e indefinido, se a hipertrigliceridemia constitui um risco independente de coronariopatia.

\section{Hipertensão e obesidade}

Como já comentamos, a elevação de pressão arterial é comumente associada à obesidade. Em estudo conduzido em Ribeirão Preto, Dressler et $\mathrm{al}^{5} \mathrm{ob}-$ servaram correlação significativa entre pressão arterial sistólica, diastólica e IMC. Alguns resultados relatando a alta prevalência de hipertensão em obesos são devidos, em parte, às dificuldades técnicas na medida da pressão arterial, neste grupo populacional. O uso de técnicas e manguitos com tamanhos apropriados reduz bastante a prevalência e o grau de hipertensão, contudo, não deixa de demonstrar a associação entre níveis pressóricos e obesidade ${ }^{6}$.

As causas de hipertensão em obesos não são claras. Alguns trabalhos clássicos descrevem a elevação da pressão arterial com o ganho de peso. Por outro lado, a redução do peso reduz os níveis pressoricos. Reisen et $\mathrm{al}^{7}$ documentaram que a redução de peso associa-se com redução do volume sanguíneo, do vo- lume minuto cardíaco e da atividade simpática. Essas duas últimas variáveis são influenciadas, significativamente, pela quantidade de sódio corporal total e por fatores neuro-hormonais. Dahl et $\mathrm{al}^{8}$ sugerem que a perda de sódio, e não a perda de peso, como responsável pela redução dos níveis pressóricos em obesos recebendo dietas hipocalóricas. Para alguns autores, e entre eles De Fronzo ${ }^{9}$, a hipertensão do obeso associa-se à hiperinsulinemia. A elevação na insulinemia, é responsável por modificações no transporte renal de sódio. A redução na excreção de sódio, provocada pela insulina, independe da glicemia. Podemos, baseados nestas observações, pensar que a hiperinsulinemia da obesidade eleva a pressão arterial por aumentar a reabsorção de sódio que eleva conseqüientemente o volume extracelular, aumentando o volume minuto cardíaco, a resistência periférica. $\mathrm{O}$ mecanismo de participação das catecolaminas na fisiopatologia da hipertensão do obeso não está esclarecido. Alguns autores como Landsberg e Young ${ }^{10}$ relatam redução da atividade simpática com o processo de perda de peso.

Outro aspecto atual, porém bastante controvertido e não explicado, é o efeito do tipo da distribuição do tecido adiposo sobre os níveis pressóricos. Esse efeito é bem conhecido para a associação obesidade-diabetes. Bjorntorp ${ }^{11}$ relata que a obesidade do tipo central-superior tem maior associação com hipertensão, do que a obesidade com distribuição de tecido adiposo nas coxas e na região glútea. As razões para essa associação não são conhecidas.

\section{Aspectos práticos do tratamento do obeso: im- plicações no tratamento da hipertensão}

Os estudos sobre a eficiência de resposta a drogas anti-hipertensivas sugerem que a idade, fatores humorais e a excreção de sódio são determinantes potenciais para o sucesso da terapia em obesos. Poucos estudos, no entanto, abordam a influência da obesidade sobre a resposta a diferentes classes de drogas. Os poucos estudos indicam que os agentes bloqueadores de canais de cálcio, os simpatolíticos e os inibidores de enzima de conversão são, particularmente, eficientes na redução da hipertensão de obesos. A clonidina se mostrou menos efetiva que a hidroclortiazida nesse controle. Recentemente, Schmieder et al ${ }^{12}$ compararam em obesos hipertensos a efetividade dos $\beta$ bloqueadores e dos bloqueadores de canais de cálcio. Os resultados sugerem que existe para os indivíduos magros melhor resposta com os inibidores de canais 
de cálcio, enquanto que os obesos apresentam melhor resposta aos $\beta$ bloqueadores (metoprolol $50 \mathrm{mg}$ duas vezes ao dia). Não encontramos, estudos verificando possíveis efeitos dessas drogas na eficácia da terapêutica da obesidade, ou seja os efeitos dessas drogas no metabolismo energético e sua ação na velocidade de perda de peso. Não podemos nos esquecer que alguns diuréticos $\beta$ bloqueadores modificam os padrões de lipides séricos, reduzindo os níveis de HDL e elevando a trigliceridemia.

Outro aspecto que gostaríamos de ressaltar, é que, além das drogas hipotensoras, o tratamento do excesso de peso deve merecer atenção do médico que atende obesos hipertensos. Esse aspecto é muitas vezes esquecido ou a ele dada pouca ênfase, chamando-se mais a atenção à farmacoterapia da hipertensão. Para o tratamento da obesidade são utilizados dietoterapia, exercício e drogas que, de alguma maneira, interferem com o apetite ou o gasto energético. Dessas categorias terapêuticas deve-se chamar atenção especial à maneira indiscriminada com que os anorexígenos são utilizados em nosso país. Essa drogas são, em geral, derivados da anfetamina com ação simpatomimética. Devem, portanto, ser proscritas do tratamento dos obesos hipertensos, pois seu uso pode elevar os níveis pressóricos. Mais recentemente, foi introduzido no mercado um grupo de drogas, a fenfluoramina e a d-fenfluoramina, com ação mediadora no sistema serotoninergico. Essas não apresentam efeito estimulante central e, aparentemente, não elevam os níveis de pressão arterial.

Preparações com hormônio tireodeano e gonadotrofina corionica humana, muito em uso no Brasil, pelos seus riscos ou ineficácia, não têm lugar no tratamento de pacientes obesos, hipertensos ou não. Os diuréticos não devem ser prescritos com o objetivo terapêutico da obesidade, especialmene quando o paciente faz uso de dietas hipoclóricas. Nestas situações são descritos distúrbios eletrolíticos graves que podem agravar ou determinar arritmias cardíacas às vezes fatais.

Podemos, então, resumir que para os obesos hipertensos a utilização dessas drogas representa conduta perigosa e que mesmo em normotensos, elas somente devem ser prescritas por períodos curtos (30-60 dias), não constituindo, portanto, nunca a base do tratamento da obesidade.

Os programas de maior sucesso para tratamento de obesos utilizam dieta, aumento da atividade física e modificação de comportamento com suporte emocional $^{13}$.
A dietoterapia deve ser segura, nutricionalmente adequada, prática e efetiva a longo prazo (mais de 5 anos). Inúmeras formulações dietéticas buscam esses objetivos, contudo, as de maior sucesso são aquelas que conseguem modificar o hábito alimentar do obeso, transformando sua alimentação que, em geral, tem elevado teor calórico, pouco resíduo e que é ingerida com grande velocidade para uma alimentação com baixo teor calórico, com elevada quantidade de resíduo e que seja ingerida lentamente. Com essa finalidade tenta-se a redução na ingestão de gorduras $(450 \mathrm{cal} / 100 \mathrm{~g})$, doces $(390 \mathrm{Cal} / 100 \mathrm{~g})$ e carnes $(255 \mathrm{cal} / 100 \mathrm{~g})$ e o aumento na ingestão de vegetais (255 cal/100 g), frutas (38 Cal/100 g) e amiláceos $(128 \mathrm{Cal} / 100 \mathrm{~g})$. De maneira geral, a ingestão de gorduras e carnes é bastante elevada no Brasil e especial no Sul e Sudoeste. Estima-se que cerca de $40-42 \%$ das calorias de nossa dieta sejam originadas de gordura. A redução para cerca de $30 \%$, associado ao aumento na ingestão de verduras e legumes tende a reduzir, drasticamente, a ingestão calórica e de sódio, sem prejuízo significativo da saciedade e da adequação nutricional.

A atividade física pode minimizar a perda de massa muscular associada à perda de peso. A escolha de um tipo de exercício mais agradável deve ser sempre motivo de discussão com o paciente. Além dessa prática, a adoção de condutas que façam aumentar, continuamente, o gasto energético diário, como a utilização de escadas, a redução na utilização de carro etc, podem ajudar o estabelecimento a longo prazo de padrões de atividade física mais apropriados para redução e manutenção do peso.

Para a mudança de comportamento incluímos entre outras condutas, a automonitoria, por meio de registro, da ingestão de alimentos pelo menos por três meses. Pode ser instrumento útil para a adoção de hábitos alimentares compatíveis com a perda e a manutenção do peso em níveis mais apropriados.

Apesar dessas medidas, não podemos nos esquecer que existe uma forte influência genética na determinação do peso e que quando presente o seu controle torna-se mais difícil. Devemos lembrar que não existe padrão comportamental único entre os obesos e como consequiência cada paciente deve ser avaliado, cuidadosamente, na tentativa de encontrar-se determinantes do excesso de peso e tentar abordá-los por meio de programas individuais. A adoção de condutas padronizadas aumenta em muito, os riscos de insucesso de tratamento. 


\section{REFERÊNCIAS BIBLIOGRÁFICAS}

1 - NATIONAL CENTER FOR HEALTH STATISTICS. Public Health Service. Government Printing Office, Washington, 1979, Publ. № 79-1656.

2 - METROPOlitAN HEIGHT AND WERGHT TABLES. Stat Bull Metrop Life Found. 64: 3-9, 1984.

3 - MOORE FD; OLESEN KH \& MACMURREY JE. The body call mass and its supporting enviroment. W. B. Saunders, Philadelphia, 1963, p. 186.

4 - KANNEL WB; BRAND N. \& SKINNER JJ. The relation of adiposity to blood pressure and development of Hypertension. The Framingham Study. Ann Intern Med 67: 48, 1967.

5 - DRESSLER WW et al. Arterial blood pressure and modernization in Brazil Am Anthipol 89: 398, 1982.

6 - WEINSIER R; HEIMBURGER D \& BUTTEREWORTH JR. CE. Handbook of clinical nutrition. Mosby Campany. St. Luis, p. 283, 1989.
7 - REISEN E; FROLICH ED \& MESSERLI FH. Cardiovascular changes after weight reducion in obesity hypertension. Ann Intern Med 98: 315, 1983.

8 - DAHL LK; SILVER L \& CHRISTIE RW. The role of salt in the fall of boold pressure acccompany reduction in obesity. $\mathbf{N}$ Engl J Med 258: 1186, 1958.

9 - DE FRANZO RA; GOLDBERG M \& AGUS ZS. The effects of glicose and insulin on renal eletrolyte transport, J Clin Invest 58: 83, 1976.

10 - LANDSBERG L \& YOUNG JB. Fasting, feeding and regulation of sympathetic nervous system. N Engl J Med 198: 1295, 1978.

11 - BJORNTORP P. Regional patterns of fat distribuition. Ann Intern Med 103: 994, 1985.

12 - SCHMEIDER RE et al. Obesity as determinant for response to antihypertensive treatment. B M J 307: 537, 1993.

13 - WEINSIER EL. Obesity. In: RAKEI RE ed. CONN'S. Current Therapy. W. B. Saunders, Philadelphia USA 1990.

\section{TRATAMENTO NÃO - MEDICAMENTOSO DA HIPERTENSÃO ARTERIAL - ALCOOLISMO}

Paulo César B. Veiga Jardim

Professor Adjunto da Faculdade de Medicina da Universidade Federal de Goiás, Coordenador da Liga de Hipertensão Arterial, Pós-graduando (Doutorado) da Unidade de Hipertensão do INCOR-USP

Vários estudos epidemiológicos e clínicos mostraram uma correlação positiva entre pressão arterial e consumo de álcool ${ }^{1 / 7}$.

Alguns destes estudos indicaram que a relação entre o álcool e a hipertensão é diferente entre os homens e as mulheres ${ }^{6}$. Entre os homens, não haveria interferência com a ingestão de até 20 a $30 \mathrm{ml} / \mathrm{dia}$ (20 a 30 g/dia) e a partir daí a correlação seria linear. Entre as mulheres, parecia haver uma correlação em forma de $\mathrm{U}$ com o ponto mais baixo naquelas que ingerem até $40 \mathrm{~g}$ de álcool/semana. Estes dados referentes às mulheres não foram, entretanto, confirmados em estudos realizados em outros países ${ }^{1 / 2}$.

Podemos determinar, também, a prevalência de Hipertensão em função do hábito da ingestão de bebidas alcoólicas. Por exemplo, verifica-se que nos indivíduos de raça branca que ingerem $60 \mathrm{~g}$ ou mais de álcool, por dia, ocorre o dobro de hipertensão quando comparados com pessoas que não bebem. Este percentual é um pouco menor (só $50 \%$ a mais) quando os indivíduos são de raça negra ${ }^{1}$.

Por outro lado, a correlação álcool x hipertensão é independente de tabagismo e obesidade.
O efeito hipertensivo do álcool foi demonstrado em indivíduos normotensos por diversos estudos. Puddey et $\mathrm{al}^{6}$ mostraram uma discreta redução na pressão arterial com uma redução na ingestão de bebidas alcoólicas, particularmente na pressão sistólica. Foi, também, demonstrado em hipertensos, uma redução tanto na pressão sistólica, quanto na diastólica com a redução na "ingesta" de álcool. Por outro lado, a reintrodução de bebidas alcoólicas provocou elevação dos níveis pressóricos ${ }^{1}$.

Outro fator que merece destaque é a interferência causada pelas bebidas alcoólicas na eficácia da terapêutica anti-hipertensiva. Verificou-se que nos indivíduos, sob tratamento farmacológico, os níveis pressóricos são maiores nos períodos em que há ingestão de bebidas alcoólicas.

Ainda há muito que se esclarecer sobre os possíveis mecanismos que provocam elevação da pressão com a ingestão de álcool, regularmente. Entre as diversas possibilidades podemos citar: alterações do tônus vascular periférico e do transporte celular em musculatura lisa vascular, atenuação do mecanismo baroreceptor reflexo, ausência do relaxamento vascular dependente do endotélio, entre outros aventados.

É importante notar que os efeitos do álcool são reversíveis, no que diz respeito à hipertensão arterial.

EM RESUMO - podemos dizer que, em normotensos, o álcool pode provocar pequeno aumento 
da pressão arterial. Nos hipertensos, o álcool provoca aumento da pressão e interfere na terapêutica farmacológica $^{1 / 7}$.

Assim, para auxiliar no controle da hipertensão, o consumo de bebidas alcoólicas não deve ultrapassar $30 \mathrm{~g}$ de etanol, por dia. Este valor é o que existe em $60 \mathrm{ml}$ de bebidas destiladas ( 01 dose), ou em $240 \mathrm{ml}$ de vinho (02 taças) ou, ainda, em 720 $\mathrm{ml}$ de cerveja ( 01 cerveja grande ou 02 latas $)^{3,4,7}$.

\section{REFERÊNCIAS BIBLIOGRÁFICAS}

1 - THE NATIONAL KIDNEY FOUNDATION. Education Program on Nonpharmacologic Management of Hypertension. Summary papers and Selected Bibliographies, New York, p. 1-50, 1991.
2 - MACMAHON S. Alcohol consumption and hypertension. Hypertension 9: 111-121, 1987.

3 - II Consenso Brasileiro de Hipertensão Arterial. Hiperativo 1 (supl 1): 1-24, 1994.

4 - JOINT NATIONAL COMMITTEE ON DETECTION, EVALUATION, AND TREATMENT OF HIGH BLOOD PRESSURE THE FIFTH REPORT. National Institutes of Health, NIH Publication, 93 - 1088, 52 p. Jan. 1993.

5 - POTTER JF et al. The pressor and metabolic effects os alcohol in normotensive subjects. Hypertension 8: 625-631, 1986.

6 - PUDDEY IB et al. Evidence for a direct effect of alcohol consumption on blood pressure in normotensive men: a randomized controlled trial. Hypertension 7: 707-713, 1985.

7 - CARVALHO JGR; MULINARI RA. \& LAFFITTE A. Álcool, hipertensão arterial e sistema cardiovascular. Hiperativo 2: 26-33, 1995.

\section{O EXERCÍCIO FÍSICO NO TRATAMENTO NÃO MEDICAMENTOSO DA HIPERTENSÃO ARTERIAL}

Nereida Kilza da Costa Lima

Médica Geriatra, aluna do Curso de Pós-Graduação (nível Doutorado) da Área de Nefrologia da Faculdade de Medicina da Universidade de São Paulo

O exercício físico regular é recomendado, atualmente, na prevenção e para o tratamento não medicamentoso da hipertensão arterial. Estudos epidemiológicos recentes têm demonstrado redução no risco cardiovascular, associado ao treinamento físico em indivíduos normotensos. O exercício regular em hipertensos, além de agir em outros fatores de risco, promove discreta, porém, significativa redução nos níveis tensionais ${ }^{1}$.

Há evidências de que hipertensos e obesos têm maior porcentagem de fibras musculares estriadas do tipo IIb, que são menos vascularizadas e mais resistentes à ação da insulina na captação de glicose pelas células. O exercício físico continuado promove diminuição na proporção destas fibras, aumentando a capilarização dos músculos. Concomitantemente com a redução de peso que a atividade física regular proporciona em obesos, tal achado explica a melhora da sensibilidade à insulina, associada ao exercício crônico, com redução secundária dos níveis de insulina circulante $^{2,3}$.

Quando há queda da insulinemia, verifica-se simultâneo aumento da excreção renal de sódio e diminuição da atividade do sistema nervoso simpático, com redução do nível de noradrenalina circulante. Alguns autores atribuem estes efeitos, os quais ocorrem em situação de treinamento físico, à elevação da prostaglandina $\mathrm{E}$ circulante e não à menor insulinemia ${ }^{4}$.

Observou-se, ainda, diminuição das taxas plasmáticas de uma substância digoxina-símile endógena, após exercício físico continuado. Sabe-se que esta classe de substâncias inibe a bomba de sódio nas células, aumentando o sódio intra-celular e, consequientemente, a reatividade vascular ${ }^{5}$.

O exercício físico recomendado, atualmente, na prevenção e na terapêutica da hipertensão arterial é o do tipo aeróbio ou dinâmico, ou seja: andar acelerado, correr, nadar ou pedalar, em intensidade leve ou moderada (40 a $60 \%$ do consumo máximo de oxigênio - $\mathrm{VO}_{2}$ máx), com freqúência de 3 a 5 sessões por semana, cada uma com duração de 15 a 60 minutos. $\mathrm{O}$ exercício isométrico, do tipo anaeróbio, realizado com cargas elevadas, não tem sido recomendado por promover excessivo aumento das pressões arteriais sistólica e diastólica, durante a sessão de treinamento ${ }^{1,4}$.

Como a pressão arterial média eleva-se, também, na realização do exercício aeróbio, porém de forma mais branda, deve-se verficar a pressão arterial dos indivíduos hipertensos durante o mesmo, bem como realizar avaliações clínicas periódicas. 


\section{REFERÊNCIAS BIBLIOGRÁFICAS}

1 - THE JOINT NATIONAL COMMITEE ON DETECTION. Evaluation, and Treatment of High Blood Pressure: The fifth report. Arch Intern Med 153: 154-183, 1993.

2 - FERRANNINI E. Insulin and blood pressure: Possible role of hemodynamics. Clin Exper Hypertens [A] 14: 271-284, 1992.
3 - KROTKIEWSKI M. Role of muscle morphology in the development of insulin resistance and metabolic syndrome. Presse Med 23: 1393-1399, 1994.

4 - NEGÃO CE; FORJAZ CLM \& BRUM PC. Exercício físico e hipertensão arterial. Hiperativo 1: 18-22, 1994.

5. KOGA $M$ et al. Mild Exercise decrease plasma endogenous digitalislike substance in hypertensive individuals. Hypertension 19 (suppl II): II231-II236, 1992.

\section{TRATAMENTO MEDICAMENTOSO DA HIPERTENSÃO ARTERIAL}

Oswaldo Lima Ramos

Professor Titular da Disciplina de Nefrologia da Escola Paulista de Medicina - SP

Bright, no fim do século 18, descreve que o rim de pacientes com insuficiência renal crônica apresentava lesões arteriais peculiares. Harvey descobriu a circulação do sangue e Halley mediu pela primeira vez a pressão arterial em um cavalo. No fim do século XIX, Mahomed descreveu a síndrome arterial hipertensiva. Em 1881, Riva Rocci cria o primeiro esfignomanômetro e, em 1906, Karotkoff torna prática a medida de pressão arterial. Em 1914, Volhard descreve as síndromes de hipertensão maligna e benigna. Goldblatt, em 1934, descreve a hipertensão renovascular e, em 1939, Page e Braun - Menendez descobrem a angiotensina; Cohn, em 1955, descreve o hiperaldosteronismo e em 1959, fica clara a interrrelação entre angiotensina e a aldoesterona.

Em 1939, a American Heart Association e a Society of Great Britain and Ireland padronizaram os métodos de determinação de pressão arterial. Em 1949, criou-se o Council for High Pressure Research concentrando a pesquisa sofisticada em hipertensão.

As pesquisas conduziram à descoberta dos receptores simpáticos específicos, dos canais de cálcio, dos canais de potássio, dos inibidores do sistema renina angiotensina e, finalmente, estão surgindo as primeiras conquistas através da biologia molecular.

No concernente à terapêutica da hipertensão arterial, salienta-se que, em 1876, Ambard descobriu que os hipertensos excretavam menos cloreto pela urina e, em 1922, Allen padronizou o tratamento da hipertensão utilizando dietas pobres em sal. Surgiram dúvidas se baixar a pressão seria benéfico ou malefíco para os pacientes hipertensos. Van Slyke demonstrou que a baixa da pressão, utilizando tiocianeto de potássio, não diminuía a depuração renal desde que ha- via um mecanismo de auto-regulação da circulação a este órgão.

Na década de 40, já era consenso que o aumento da pressão deveria ser tratado e que três linhas terapêuticas eram utilizadas, a saber: psicoterapia, dieta extremamente baixa em sódio (dieta de arroz) e simpatectomia lombo dorsal. Na década de 50, surgiram as primeiras drogas que, efetivamente, controlavam a pressão arterial elevada, tais como a reserpina, os bloqueadores ganglonares a hidralazina e os saluréticos. Em 1960, Pereira, respeitável hipertensólogo, não encontrou diferença significativa de prognóstico na sobrevida entre a população hipertensa tratada e não tratada. Estudos epidemiológicos iniciados em 1972, pelo The National High Blood Pressure Educational Program mostraram à sociedade que o tratamento era altamente efetivo, prevenindo complicações e aumentando a sobrevida. Assim sendo, no quinto relato de JNC ficou claro que, com o tratamento, houve queda de $50 \%$ da mortalidade por acidente vascular cerebral e de $45 \%$, por doença coronária.

A grande eficiência das drogas existentes, hoje, para o tratamento de hipertensão induziria a se pensar que a terapêutica desta doença fosse problema, totalmente, resolvido. Tal fato não é verdadeiro devido às seguintes características da doença hipertensiva: embora a sua prevalência seja muito alta (15\% da população adulta) a doença é, em geral, assintomática pelo menos no seu início; na grande maioria dos casos, não há tratamento que induza à cura completa, exigindo que este se prolongue por toda a vida; as medicações utilizadas, muitas vezes, provocam efeitos colaterais indesejáveis induzindo mais facilmente à interrupção do tratamento. Estas características explicam porque apenas uma minoria $( \pm 25 \%)$ dos hipertensos recebem tratamento adequado.

O tratamento do hipertenso implica em medidas profiláticas que incluem uma readaptação do estilo de 
vida, a instituição de terapêutica não farmacológica e, quando necessário, na utilização de drogas.

Este tratamento visa, fundamentalmente, a normalização da pressão, no sentido de proteger os órgãos alvos especificamente cérebro, rim, coração e vasos. Além disto, é também importante que este tratamento elimine os fatores de riscos adicionais, tais como obesidade, diabetes, hiperlipemia e hiperuricemia.

Qualquer esquema terapêutico que controle os níveis pressóricos seria adequado, porém, cada uma das medicações utilizadas têm características que as tornam mais úteis em situações específicas.

Assim sendo, poder-se-ia enumerar as vantagens e desvantagens do tratamento efetivado pelas drogas mais utilizadas em nosso meio.

Os anti-hipertensivos atuais podem ser classificados em 5 classes a saber: 1. Diuréticos; 2. simpaticolíticos, que se subdividiram em centrais e os beta e alfa bloqueadores; 3. Vasodilatadores; 4. Antagonistas de cálcio; 5. Inibidores da angiotensina, subdivididos em inibidores da enzima conversora e dos receptores de angiotensina.

Cada uma destas drogas tem vantagens e desvantagens, quando comparadas entre si. Os diuréticos detêm a mais longa experiência mundial, são eficientes como monoterapia, com baixa freqüência de escape e têm preço baixo e, como desvantagem, apresentam o fato de, eventualmente, poderem provocar alterações glicídicas, lipídicas e eletrolíticas, assim como ativarem o sistema renina-angiotensina, sendo ainda pouco ativos na reversão da hipertrofia cardíaca.

Os simpatolíticos de ação central, também, são usados desde longa data, têm raras contra-indicações formais e revertem a hipertrofia ventricular esquerda porém, em contrapartida, têm menor eficiência como monoterapia, alteram o perfil metabólico glicídico e lipídico e apresentam efeitos colaterais não desprezíveis.

Os betabloqueadores são eficientes como monoterapia e, ainda, eficazes na prevenção de isquemia miocárdica, têm custo baixo, longa experiência mundial, apresentando ações benéficas adicionais favoráveis na coronariopatia, porém, não há certeza de que reduzam a hipertrofia cardíaca. As desvantagens são inerentes a sua ação farmacológica, sendo contra-indicados na presença de broncoespasmo, insuficiência cardíaca e vascular periférica, além disto podem provocar sono e fadiga excessiva e alterar o perfil metabólico e o desempenho físico.

Os alfa bloqueadores têm excelente perfil metabólico e hemodinâmico, sendo a experiência mundial razoável. As desvantagens decorrem de ter baixa eficiência como monoterapia, apresentarem efeitos colaterais e taquifilaxia, tornando difícil o manuseio de suas dosagens.

Os vasodilatadores, mesmos os mais modernos, devem ser usados em associação a outras drogas, pois têm como inconveniente a estimulação simpática e a retenção hídrica, além de não regredirem a hipertrofia ventricular esquerda.

Os antagonistas de cálcio têm boa experiência mundial, são eficientes como monoterapia, regridem a hipertrofia ventricular esquerda e têm ação benéfica na presença de coronariopatia. Apresentam, em contrapartida, alguns efeitos colaterais, interagem, desfavoravelmente, com os betabloqueadores e têm ação não definida sobre alterações metabólicas.

Os inibidores de enzima conversora têm alta eficiência como monoterapia, bom perfil metabólico e hemodinâmico, provocam reversão da hipertrofia ventricular esquerda e são efetivos na proteção de órgãos alvos, particularmente do rim. Têm como inconveniente o aparecimento de tosse renitente que, por vezes, obriga a se descontinuar a medicação. A recente disponibilidade de inibidores do receptor de angiotensina contorna este inconveniente. Por outro lado, estas drogas, ao contrário dos inibidores de enzima conversora, não aumentam a disponibilidade da brandicina, cuja validade no tratamento não está completamente dimensionada. 